\title{
An Investigation of the Changes in the Natural Frequency of a Pile affected by Scour
}

\author{
Prendergast, L.J., ${ }^{\mathrm{a}, 1}$, Hester, D. ${ }^{\mathrm{b}, 2}$, Gavin, K., ${ }^{\mathrm{a}, 3}$, O’Sullivan, J.J.,
}

${ }^{a}$ School of Civil, Structural and Environmental Engineering, University College Dublin,

Newstead,

Belfield,

Dublin 4,

IRL

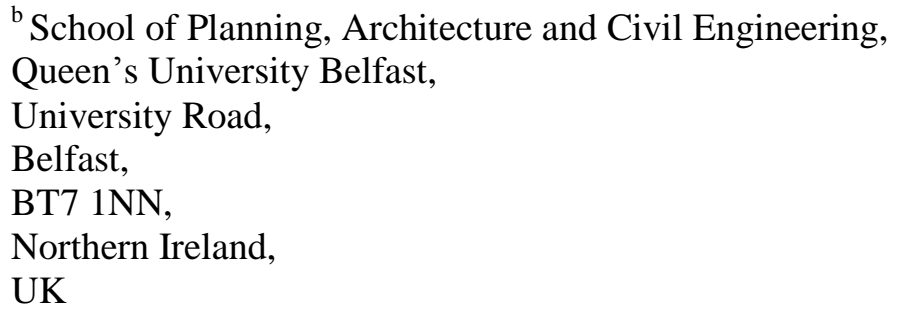

${ }^{1}$ Corresponding author

Phone: ${ }^{1}+353-1-7163231 /{ }^{3}+353-1-7163222$

Email: ${ }^{1}$ luke.prendergast@ucdconnect.ie, ${ }^{2}$ d.hester@qub.ac.uk, ${ }^{3}$ kenneth.gavin@ucd.ie, ${ }^{4}$ ji.osullivan@ucd.ie

\begin{abstract}
Scour around bridge foundations is one of the leading causes of bridge failure. Up until recently, the monitoring of this phenomenon was primarily based around using underwater instrumentation to monitor the progression of scour holes as they develop around foundation systems. Vibration-based damage detection techniques have been used to detect damage in bridge beams. The application of these vibration based methods to the detection of scour has come to the fore in research in recent years. This paper examines the effect that scour has on the frequency response of a driven pile foundation system, similar to those used to support road and rail bridges. The effect of scour on the vibration characteristics of the pile is examined using laboratory and field testing. It is clear that there is a very clear reduction in the natural frequency of the pile as the severity of scour increases. It is shown that by combining state-of-the-art geotechnical techniques with relatively simple finite element modelling approaches, it is possible to accurately predict the natural frequency of the pile for a given scour depth. Therefore, the paper proposes a method that would allow the estimation of scour depth for a given observed pile frequency.
\end{abstract}

Keywords: Scour, Vibration, Acceleration, SHM, Frequency, Bridge-Piles 


\subsection{Introduction}

Scour can be defined as the excavation and removal of material from the bed and banks of streams as a result of the erosive action of flowing water [1]. In relation to bridges local scour is focussed around piers and abutments and occurs as a result of the increased velocities and associated vortices as water accelerates around these obstructions [1]. Bed material is removed in the immediate vicinity of the structure, which can reduce the foundation stiffness and lead to catastrophic structural collapse [2]. Adverse hydraulic action, including scour, is deemed to have accounted for over $53 \%$ of a total of 500 documented bridge failures in the United States between 1989 and 2000 [3]. Larger and more frequent flood flows coupled with aging infrastructure signify that scour analysis and monitoring is becoming increasingly important in modern times [4]. There are two primary methods of combatting the effects of scour: the use of hydraulic and structural countermeasures. Both of these methods are outlined briefly below. In tandem with the provision of scour countermeasures, it is useful to monitor the presence and severity of scour so that effective scour mitigation regimes may be employed as part of a bridge management scheme. The current study is concerned with developing new scour monitoring techniques; therefore more attention is focussed on describing the current state-of-the-art in this area.

Hydraulic countermeasures: These primarily involve maintaining larger bridge openings at the bridge design stage by reducing the size of piers or by streamlining structural elements to avoid rapid flow expansion or contraction [5].

Structural countermeasures: At the design stage, this involves ensuring that spread footings are located below the maximum design scour depth [5]. Heidarpour et al highlight that the addition of riprap, rock armour or collars [6] around bridge piers also helps to mitigate the effects of scour.

Scour Monitoring: The accurate assessment and monitoring of existing structures to progressive scour has come to the fore of research in recent years $[7,8]$. A myriad of current technology aims to detect the existence and severity of scour around the foundation systems of existing bridge structures. Most of these technologies comprise underwater instrumentation that aim to monitor the evolution of scour holes over time. A brief summary of available instrumentation is given herein. The use of float-out devices [9] and Tethered Buried Switches [10] positioned in the soil near a bridge pier can provide a simple method of scour monitoring. These devices float out when the scour depth reaches their position and are programmed to send a remote signal to provide a warning. However, they require reinstallation upon floating out, which is a distinct disadvantage. Time Domain Reflectometry (TDR) aims to detect changes in the dielectric permittivity constants between materials that would occur at a water-sediment interface and thus has been used to detect scour [10 - 12]. Devices using this method work very well at detecting the depth of scour in a particular location, but require costly underwater installations and are also susceptible to background radiation. Ground Penetrating Radar (GPR) is an effective tool for the immediate monitoring of scour-critical foundation systems [7, 13]. A GPR 
transmitter can establish a high resolution profile of the river bottom and subterranean lithology at a location of interest. It is particularly good at detecting where larger previous scour holes have existed and become filled in upon the subsidence of flood waters. However, it cannot be used as a continuous monitoring tool and cannot be employed during times of high flood flow, when scour is most critical. Buried mechanical devices such as Magnetic Sliding Collars utilise a weighted collar positioned around a driven rod that falls relative to the rod as the bed level decreases $[9,10,12]$. The collar sends a remote signal to a datalogger, indicating its depth along the rod. Once the maximum scour depth is reached the collar remains at this depth, thus it requires re-installation after each flood event. This makes it quite expensive to install [9]. Other driven rod systems utilise the concept of natural frequency changes due to loss of soil support to detect the presence of scour [14]. The rod itself vibrates due to fluid-structure interaction and this vibration is used to back-correlate a scour depth. This sensor is quite good at showing the progression of scour depth with time.

Most of the aforementioned instrumentation requires either expensive underwater installation or are only suitable for discrete usage. As a result, methods of non-intrusive superstructure monitoring using vibration-based techniques have become more popular in recent times. The overall response of a bridge to both static and dynamic loads is influenced by the soil-structure interaction as recognised by [15]. The exact interaction process is quite complex and is governed by many different parameters. Accelerometers placed on bridge piers can detect fluctuations in the fundamental dynamic characteristics that are governed by changes in the foundation support scheme caused by scour. The dynamic response of a bridge pier will be strongly affected by the presence of a scour hole, even if filled, since the stiffness of the fill material may be lower than that of the previous in-situ soil. A number of authors have investigated the feasibility of using bridge dynamic measurements to detect the presence of scour. For example, a case history of a bridge in Northern Italy where one of the supporting piers was severely affected by scouring during a flood in 2000 is presented in [15]. The pier underwent marked rotations and subsequently translated over a period of time and ultimately had to be replaced. A dynamic survey to establish the modal parameters was conducted both before and after the pier retrofit with the aim of observing the changes caused by scour. Traffic induced vibrations were used to obtain the modal response of the bridge spans and the dynamic response of the bridge pier-foundation system. The research concluded that the presence of scour was detectable, but not necessarily the actual extent of the scour. A major investigation by [10] looked at the possibility of using accelerometers placed on bridge piers to monitor the progression of scour. A scaled bridge was constructed in a large hydraulic flume for two structural cases: the first with a shallow foundation, the second with a deep foundation. The dynamic response of the pier to induced impact loading (to represent traffic) was monitored as scour depths increased under laboratory control. By analysing the frequency response, it was concluded that accelerometers showed significant potential at detecting scour at laboratory scale. However, significant further work would be required to overcome 
some of the issues of instrumenting full scale structures such as low excitation due to traffic, low signal to noise ratios, and the amount of energy required to store and transmit accelerometer data [10]. The issue of environmental effects on the measured frequency of structures is also a factor [16]. A laboratory regime is reported in [12] where a series of vibration-based damage detection techniques were applied to the case of monitoring the effects of scour on the supports of a laboratory scale coastal bridge. The model bridge piers were in effect piles that extended up to the deck soffit and were fixed at the base. No attempt was made to model the soil-structure interaction. Scour was modelled as an increase in the effective length of the intermediate pile supports at the centre of the bridge. The author concluded that the mode shapes and natural frequencies in the horizontal direction were very sensitive to the progression of scour. As the free pile length was increased, a reduction in the natural frequency was observed.

Following on from the above documented research, there is a general agreement that scour may be detected using changes in the natural frequency of the structure. In this paper, the effect of scour on a piled foundation system is closely investigated through scaled experimental tests in the laboratory and full-scale field tests. The top of the pile is excited using an impulse force. The resulting acceleration response is recorded. This is undertaken at a number of scour depths. The natural frequency for a given scour depth can be determined using a Fourier transform. The effect of scour can be observed through the decrease in natural frequency as the depth of scour increases. The novelty in this paper is the development of a numerical model encapsulating the soil-structure interaction that allows for the estimation of the depth of scour based on a given observed natural frequency, using accelerometers placed on the foundation structure.

In reality, the dynamic response of a bridge pile will be strongly affected by the presence of the superstructure. This study serves as a preliminary assessment for a single pile, in order to develop the methods required to detect the presence of scour. Further research is required to apply the concepts developed herein to the monitoring of scour around full scale structures. 


\subsection{Method}

\subsection{Laboratory Model}

A laboratory scale model of a pile foundation structure was constructed in order to assess the plausibility of measuring changes in natural frequency due to progressive scour. The pile was installed in a sand matrix, which was housed in a steel mould. The pile was left to protrude approximately half its length above the sand (See Fig. 1). The pile is a $100 \mathrm{~mm}$ x $100 \mathrm{~mm}$ steel square hollow section with a Young's modulus (E) value of $2 \times 10^{11} \mathrm{~N} \mathrm{~m}^{-2}$.

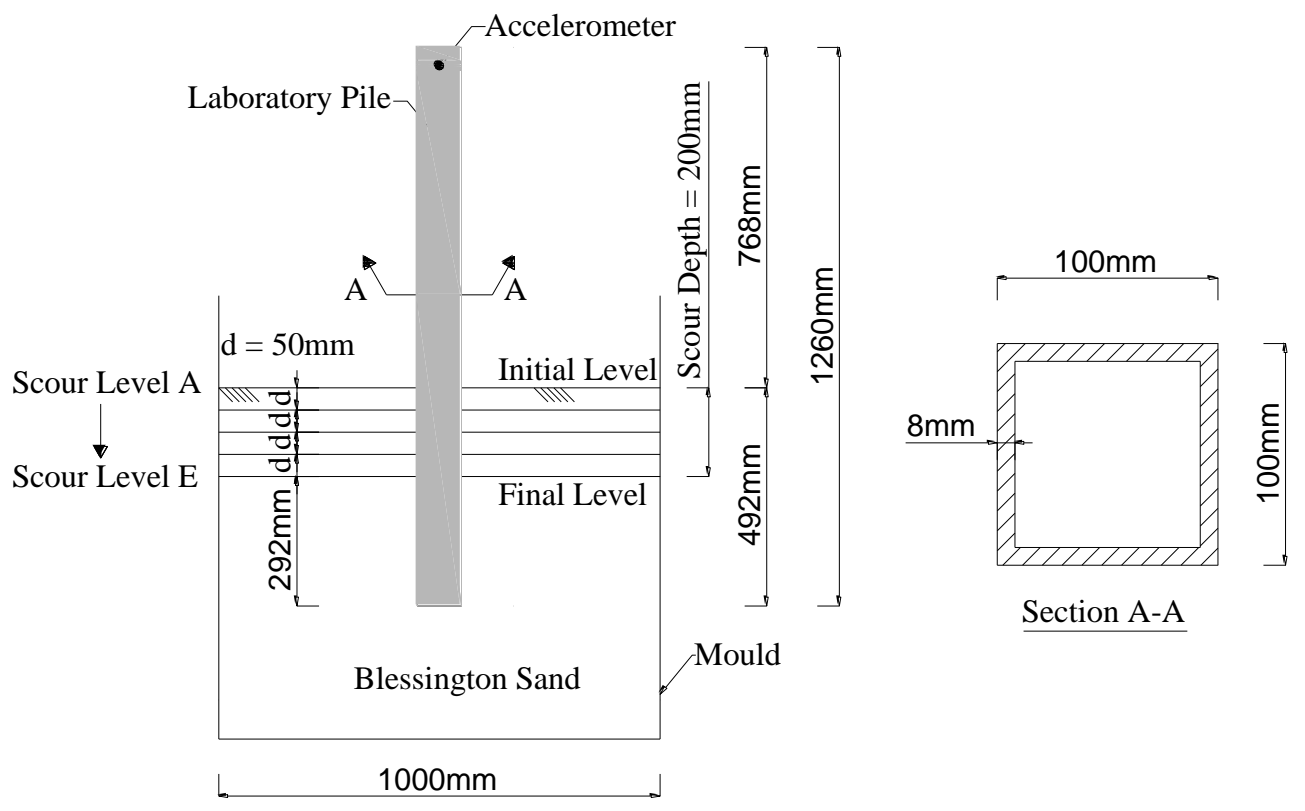

Fig. 1. Laboratory Model Geometry.

The mould used was a $1 \mathrm{~m} \times 1 \mathrm{~m} \times 1 \mathrm{~m}$ steel box. It was chosen as its high mass and stiffness provided a rigid structural framework in which to conduct dynamic testing. The mould was incrementally filled with Blessington sand (Co. Wicklow, Ireland). The sand was compacted in increments of $100 \mathrm{~mm}$. The sand had a bulk density of $2.03 \mathrm{Mg} \mathrm{m}^{-3}$ and a specific gravity value of 2.69. A sieve analysis was undertaken on the sand to establish its grading. Once the steel box had been filled to an initial level of $300 \mathrm{~mm}$, the pile was placed in the centre. Sand was then added in further $100 \mathrm{~mm}$ increments until a final fill level of approximately $800 \mathrm{~mm}$ had been reached. The sand was compacted to a high value of relative density (close to $100 \%$ ).

A uniaxial accelerometer was installed at the top of the box section as shown in Fig. 1. The accelerometer is a capacitive spring-mass system with integrated sensor electronics fabricated by Sensor's UK. A full list of its technical specifications is available online [17]. 
The accelerometer was programmed into a Campbell Scientific CR9000x Datalogger using accompanying Loggernet software. The software was programmed to take data samples at a scanning frequency of $1000 \mathrm{~Hz}$. This was adequate in order to receive a relatively full waveform such that effective post-processing may be undertaken.

The system was excited using an impulse force. For the purpose of consistency, the force was applied using a swinging arc mechanism, where a known weight was allowed to swing through a fixed arc. The force was applied in the plane of the accelerometer. Once the impulse force was applied, the system responded transiently [18]. It was the transient response that underwent post-processing in MATLAB in order to assess the relevant dynamic characteristics such as natural frequency and damping ratio.

The scour process was modelled as the incremental removal of sand from around the pile. The experiment commenced at Level A (see Fig. 1), which corresponded to the initial ground level. Sand was removed in $50 \mathrm{~mm}$ increments until a total of $200 \mathrm{~mm}$ of sand had been removed (Level E). At each level, the impulse force was applied and the acceleration response recorded. Fig. 2(a) shows the acceleration response for Scour Levels A and E respectively. It can be seen from the figure that the period between successive oscillations is larger for Scour Level E than for Scour Level A. The natural frequency at each scour level was obtained using a Fourier transform. Fig. 2(b) shows the frequency content of the acceleration signals shown in Fig. 2(a). In Fig. 2(b), it can be seen that there has been a clear reduction in frequency between Scour Levels A and E. Similar Fourier transforms were carried out on the acceleration signals recorded at all other scour levels between A and E. Fig. 2(c) shows the frequency observed at each scour level. There is a clear reduction in frequency as the depth of scour increases. 
(a)

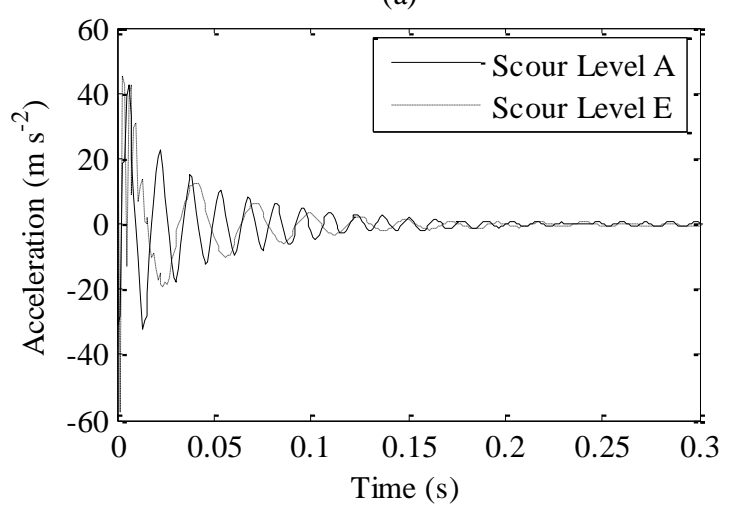

(b)

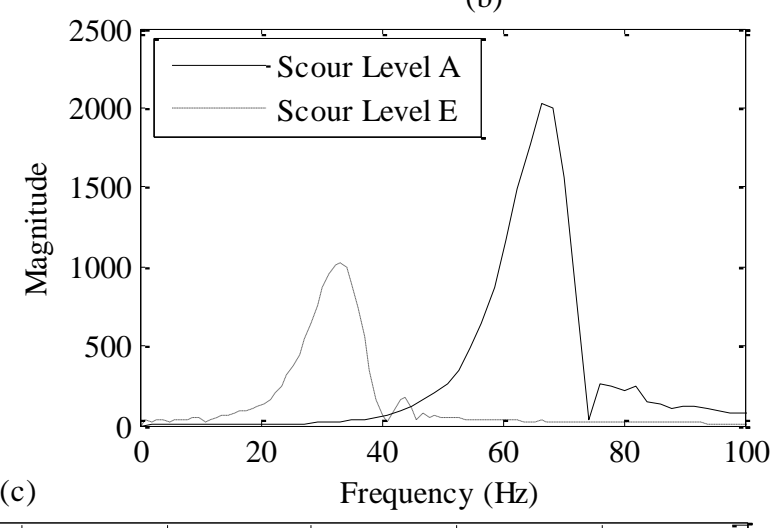

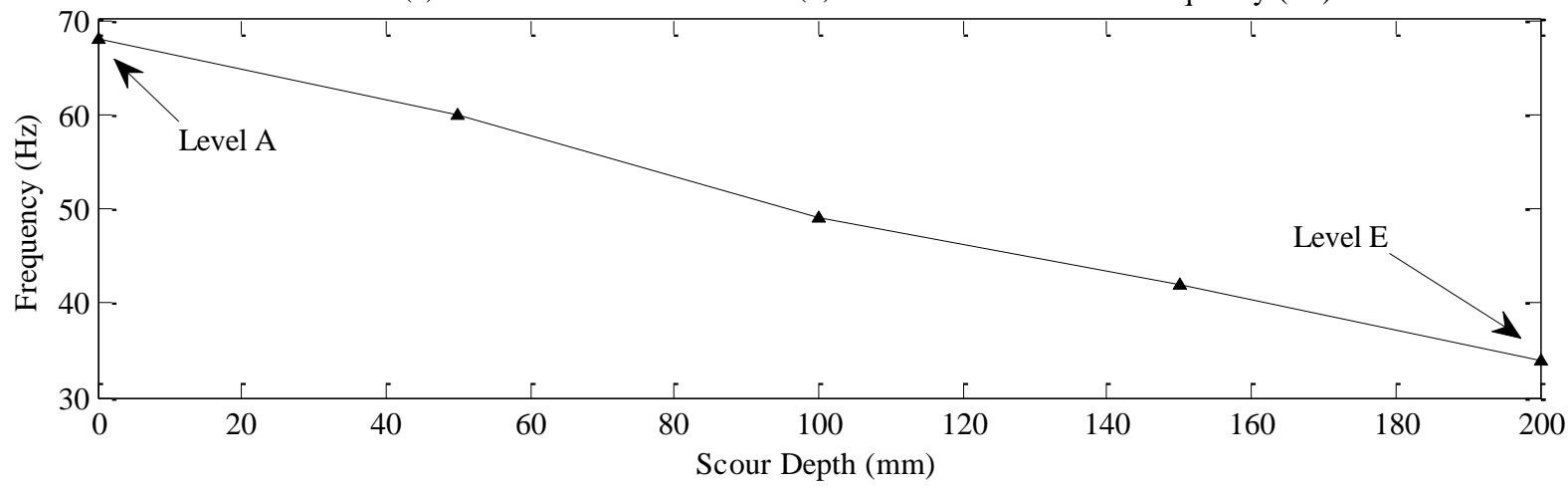

Fig. 2. Frequency Change with Scour. (a) Acceleration Response at Scour Levels A and E;

(b) Frequency Content of Signals shown in (a); (c) Change in Frequency with Scour.

The detection of scour using changes in natural frequency of a pile will, in reality, take place under water. It is important to assess the effect that this water will have on the natural frequency of the pile, as this may have an effect on the ability of the proposed approach to identify the occurrence of scour. The sensitivity of the proposed technique to the presence of water was investigated via laboratory experimentation. Three different cantilever structures were fabricated with increasing flexural rigidity (EI). Each section had a length of $1.26 \mathrm{~m}$ and a width of $0.1 \mathrm{~m}$. The geometric properties of each are detailed in Table 1 and shown graphically in Fig. 3 (Fig. 3 also shows the direction of vibration of the sections). The sections were welded to baseplates such that they could be fixed in place at the base of a $\left(1 \mathrm{~m}^{3}\right)$ tank that was subsequently filled with water. A vibration testing regime was implemented whereby all three sections were displaced then released and the resulting acceleration recorded. These acceleration signals were subsequently analysed using a Fourier transform to determine the natural frequency of the system. The sections were tested in air and in water and the natural frequency of the section in both mediums was obtained. To ensure that the results obtained experimentally were sensible, they were compared to the analytically calculated frequency, obtained using the well-known expression shown in Eq. (1).

$$
f_{1}=\frac{1}{2 \pi}(1.875)^{2} \sqrt{\frac{E I}{\rho A L^{4}}}
$$


where $f_{1}$ is the first natural frequency of the cantilever $(\mathrm{Hz}), \mathrm{E}$ is the Young's modulus $\left(\mathrm{N} \mathrm{m}^{-2}\right), \mathrm{I}$ is the moment of inertia of the cross-section $\left(\mathrm{m}^{4}\right)$. The results of the investigation are shown in Table 2.

Table 1 Test Cantilever Properties

\begin{tabular}{|l|l|l|l|l|l|l|}
\hline Section: & Length $(\mathbf{m})$ & Width (m) & $\begin{array}{l}\text { Depth } \\
(\mathbf{m})\end{array}$ & $\begin{array}{l}\text { Thickness } \\
(\mathbf{m})\end{array}$ & $\begin{array}{l}\text { Flexural } \\
\text { Rigidity }(\mathbf{E I}) \\
\left(\mathbf{N ~ m}^{2}\right)\end{array}$ & $\begin{array}{l}\mathbf{E I} / \mathbf{L} \\
(\mathbf{N} ~ \mathbf{m})\end{array}$ \\
\hline $\begin{array}{l}\text { Stiff } \\
\text { Section }\end{array}$ & 1.26 & 0.1 & 0.1 & 0.008 & $8.37 \mathrm{E}+05$ & $6.64 \mathrm{E}+05$ \\
\hline $\begin{array}{l}\text { Stiff- } \\
\text { Flexible } \\
\text { Section }\end{array}$ & 1.26 & 0.1 & 0.05 & 0.006 & $1.28 \mathrm{E}+05$ & $1.01 \mathrm{E}+05$ \\
\hline $\begin{array}{l}\text { Flexible } \\
\text { Section }\end{array}$ & 1.26 & 0.1 & - & 0.0065 & $4.58 \mathrm{E}+02$ & $3.63 \mathrm{E}+02$ \\
\hline
\end{tabular}

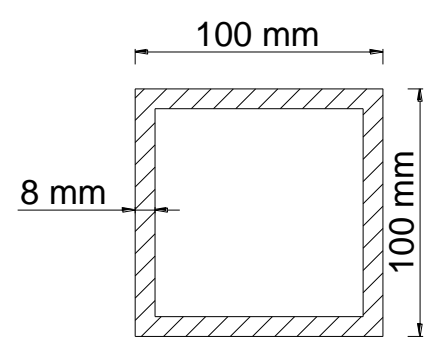

(a)

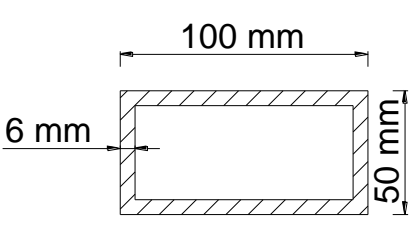

(b)

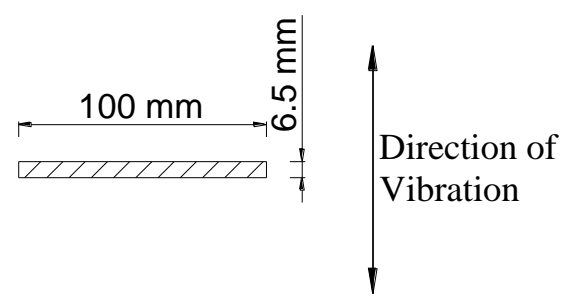

(c)

Fig. 3. Cross-section properties used in Experimental Vibration Test. (a) Stiff Section; (b) StiffFlexible Section; (c) Flexible Section.

Table 2 Experimental Results

\begin{tabular}{|l|l|l|l|l|}
\hline Section: & $\begin{array}{l}\text { Analytical } \\
\text { Cantilever } \\
\text { Frequency }(\mathbf{H z})\end{array}$ & $\begin{array}{l}\text { Avg. Frequency } \\
\text { measured in Air } \\
\text { (Hz) } \pm \text { Standard } \\
\text { Dev. }\end{array}$ & $\begin{array}{l}\text { Avg. Frequency } \\
\text { measured in } \\
\text { Water }(\text { Hz) } \pm \\
\text { Standard Dev. }\end{array}$ & $\begin{array}{l}\text { Percentage } \\
\text { Change in } \\
\text { Natural } \\
\text { Frequency } \\
\text { between air and } \\
\text { water }(\%)\end{array}$ \\
\hline Stiff Section & 67.1 & $64.9 \pm 1.23$ & $64.7 \pm 1.04$ & 0.3 \\
\hline $\begin{array}{l}\text { Stiff-Flexible } \\
\text { Section }\end{array}$ & 35.0 & $28.81 \pm 0.17$ & $27.1 \pm 0.07$ & 6 \\
\hline $\begin{array}{l}\text { Flexible } \\
\text { Section }\end{array}$ & 3.3 & $3.052 \pm 0.0$ & $2.81 \pm 0.0$ & 8 \\
\hline
\end{tabular}


Table 2 displays the values of the measured change in frequency between all three structures vibrating in air and in water. The difference between the analytical frequency and the actual frequency measured in air arises due to the difficulty in fabricating a fully rigid baseplate connection. It can be seen that the first natural frequency of the flexible structure is much more affected by the presence of water than the first natural frequency of the stiff structure, with changes of $8 \%$ and $0.3 \%$ respectively. Bridge piles are far stiffer than the sections tested experimentally therefore it is assumed that the first natural frequency of a submerged pile will be very close to the first natural frequency observed if the pile was vibrating in air.

\subsection{Field Test}

A full scale field test was undertaken at the University College Dublin (UCD) dense sand test site which is located in Blessington approximately $25 \mathrm{~km}$ southwest of Dublin City. The test bed was developed over the past ten years and has been used for a number of model, prototype and full-scale foundation experiments [19-22]. The ground conditions at the site have been described in detail by $[19,23]$. The site is comprised of a very dense, fine sand deposit with a relative density between $90 \%$ and $100 \%$, as determined from sand replacement tests. Particle size distribution analyses performed on samples taken from depths ranging from $0.7 \mathrm{~m}$ to $2 \mathrm{~m}$ below ground level (bgl) indicated that the mean particle size, $\mathrm{D}_{50}$, varied between $0.1 \mathrm{~mm}$ and $0.15 \mathrm{~mm}$. The well-graded angular sand had a fines content (percentage of clay or silt particles) of between 5\% and 10\%. Samples typically had less than $10 \%$ coarse-grained particles $(>0.6 \mathrm{~mm})$. The equilibrium ground water table is approximately $13 \mathrm{~m}$ below ground level. The sand is partially saturated, with the degree of saturation above the ground water table being $63 \%$ to $75 \%$. The natural water content was relatively uniform at $10 \%-$ $12 \%$ above the water table and was found not to vary seasonally. The sand has a bulk density in the region of $2.10 \mathrm{Mg} \mathrm{m}^{-3}$, a unit weight of $19.8 \mathrm{kN} \mathrm{m}^{-3}$, a constant volume friction angle of $37^{\circ}$ and a peak friction angle which ranges from $54^{\circ}$ to approximately $40^{\circ}$ over the depth of interest in this paper $[22,24]$. The specific gravity of particles was 2.69. The maximum and minimum void ratios were 0.73 and 0.37 respectively. Ten Cone Penetration Tests (CPT) were performed at the site. The average CPT tip resistance $\left(\mathrm{q}_{\mathrm{c}}\right)$ profile is shown in Fig. 4(a), along with the maximum and minimum measured $\mathrm{q}_{\mathrm{c}}$ values. The values are relatively consistent revealing a uniform sand deposit where $\mathrm{q}_{\mathrm{c}}$ increased from $\approx 10 \mathrm{MPa}$ at ground level to $\approx 17 \mathrm{MPa}$ at $2 \mathrm{~m}$ below ground level, thereafter increasing gradually with depth. The shear wave profile measured using the multi-channel analysis of surface waves (MASW) method [25] for the site is shown in Fig. 4(b). The small-strain shear modulus $\left(\mathrm{G}_{0}\right)$ profiles derived from the profiles in Fig. 4(a) and (b) are shown in Fig. 4(c). Given the unit weight of the sand is $\approx 20 \mathrm{kN} \mathrm{m}^{-3}$, it is easy to derive the small-strain shear modulus from the $\mathrm{V}_{\mathrm{s}}$ measurements [25]. The variation of $\mathrm{G}_{0} / \mathrm{q}_{\mathrm{c}}$ with $\mathrm{q}_{\mathrm{cl}}$ for a range of sands was examined by $[26,27]$. 
(a)

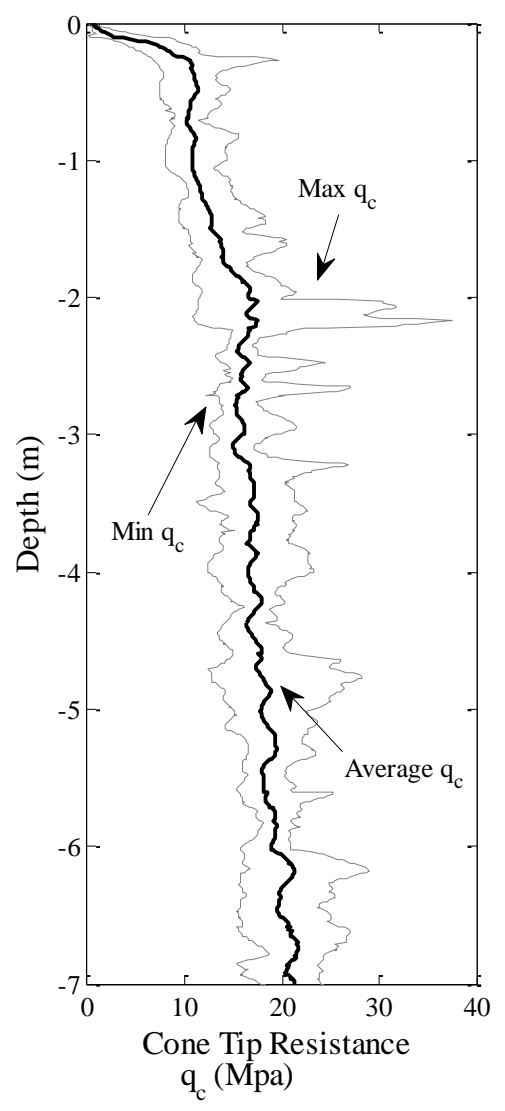

(b)

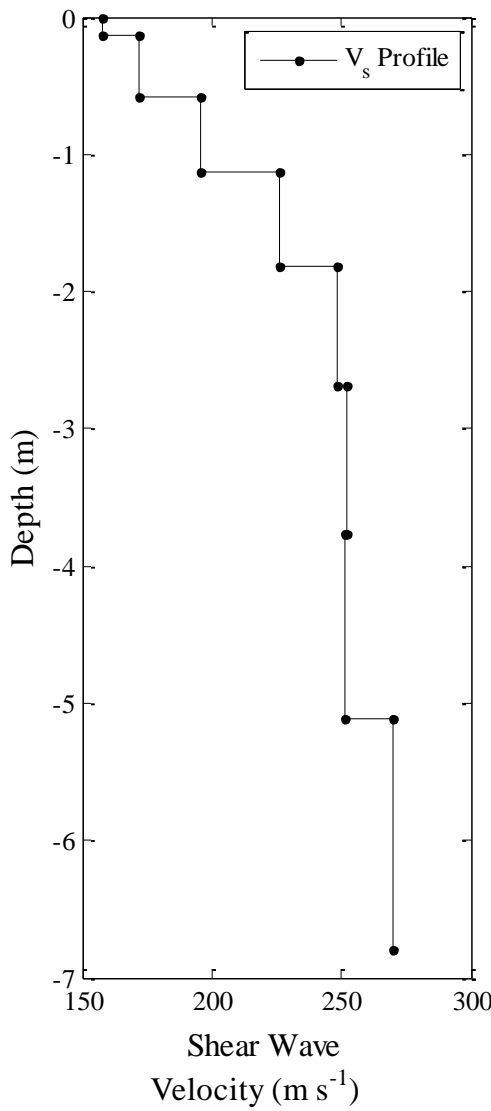

(c)

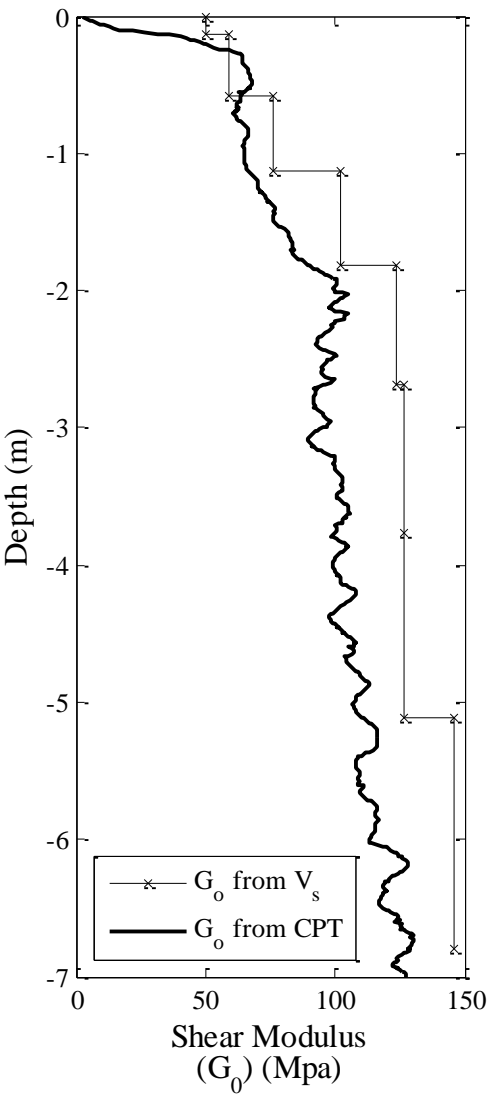

Fig. 4. Blessington Site Properties. (a) Cone Tip Resistance $\mathrm{q}_{\mathrm{c}}(\mathrm{MPa})$; (b) Shear Wave Profile $\left(\mathrm{m} \mathrm{s}^{-1}\right)$; (c) $\mathrm{G}_{0}$ Profiles (MPa).

An open-ended steel pile was installed in the sand stratum, as illustrated in Fig. 5. The steel pile has a Young's modulus (E) value of $2 \times 10^{11} \mathrm{~N} \mathrm{~m}^{-2}$. The total pile length is $8.760 \mathrm{~m}$ and, at the start of the test, the top of the pile protruded a distance of $2.26 \mathrm{~m}$ above the sand. Four accelerometers were fitted along the initial exposed length (see Fig. 5). All were hard-wired into a Campbell Scientific CR9000x datalogger. The program RTDAQ was engaged to record samples at a scanning frequency of $1000 \mathrm{~Hz}$. This scanning frequency was sufficiently high to allow for the detection of numerous vibration modes. 


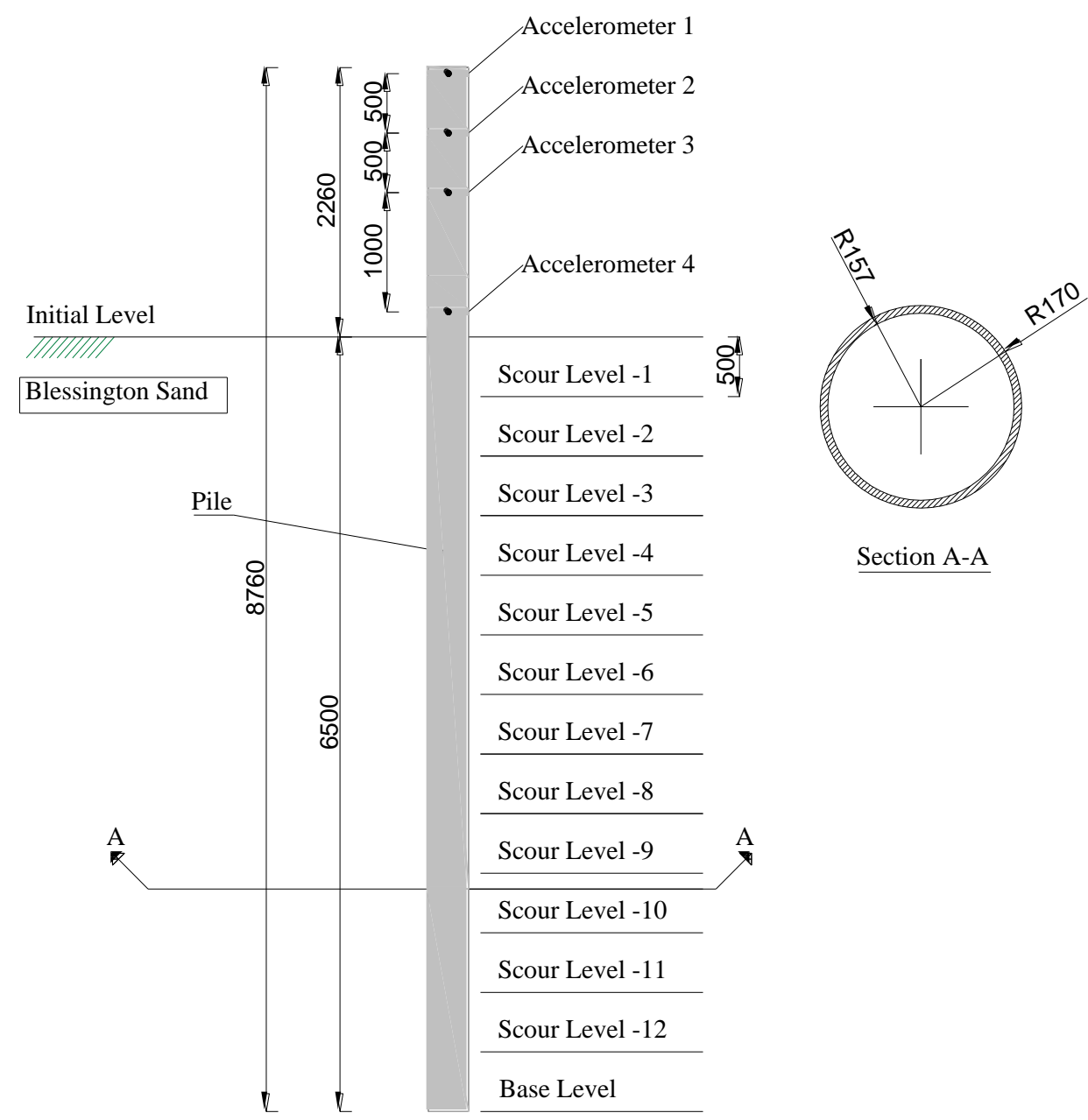

Fig. 5. Installed Pile Schematic (All dimensions are in $\mathrm{mm}$ ).

Fig. 5 shows the experimental arrangement for the full scale field test. There were thirteen scour levels tested; initial ground level and twelve scour depths. Each scour level was separated by $0.5 \mathrm{~m}$. An excavator was used to remove the sand from around the pile for each test. At each level, a lateral impulse force was applied to the top of the pile using a modal hammer and the transient acceleration response was recorded by the accelerometers. Fig. 6 gives an example of pile acceleration signals observed during the field test. (Note: the acceleration signal shown in Fig. 6 is for a Scour Level -4). 
(a)

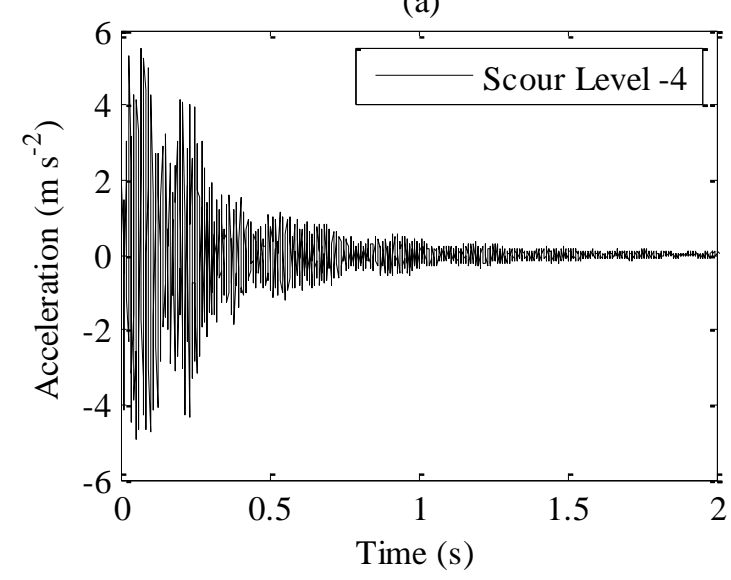

(b)

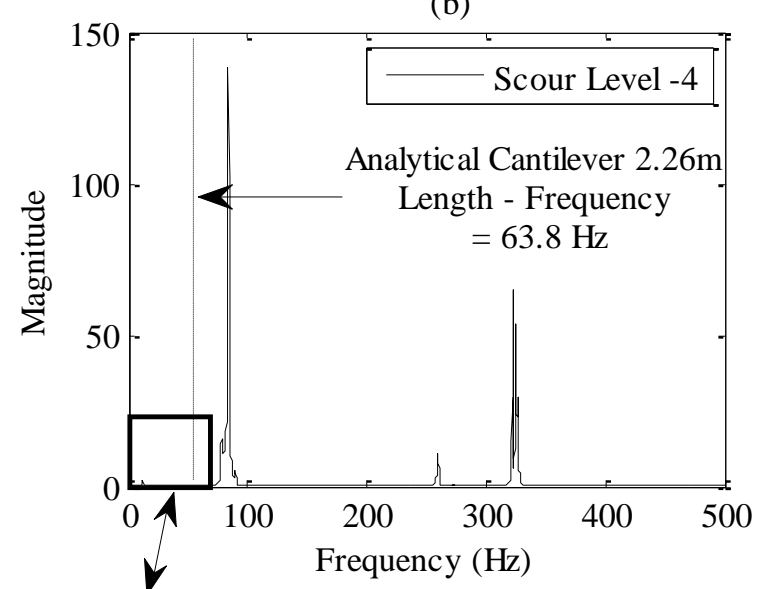

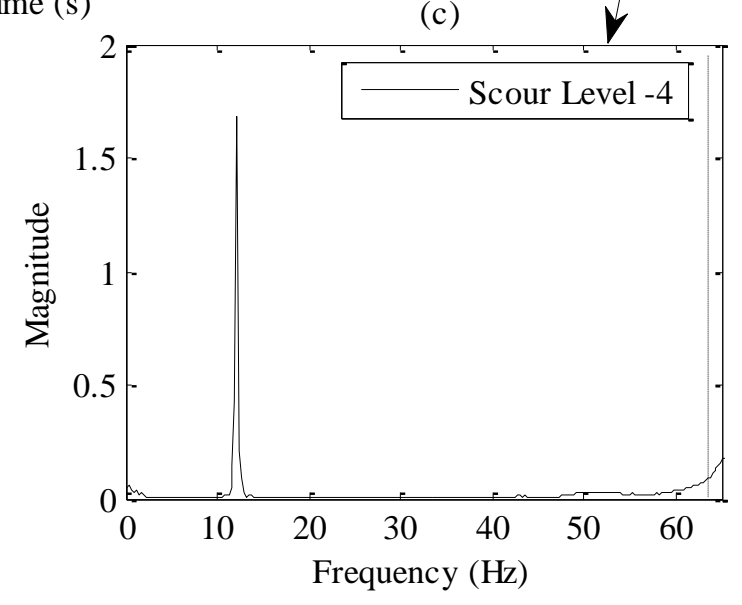

Fig. 6. Isolating Frequency Zone of Interest. (a) Acceleration Signal at Scour Level -4 ( $\left.\mathrm{m} \mathrm{s}^{-2}\right)$;

(b) Frequency Content of Signal shown in (a); (c) First Natural Frequency of pile (Hz).

Fig. 6(a) shows the time-domain acceleration response obtained from Accelerometer 1 as a result of applying a lateral impulse force to the top of the pile while testing at Scour Level -4 (See Fig. 5 for test schematic). A Fourier transform was applied to this signal to obtain the frequency content. The frequency content of the signal in Fig. 6(a) is displayed in Fig. 6(b). Two large peaks at $86 \mathrm{~Hz}$ and $322 \mathrm{~Hz}$ dominate the frequency spectrum. When the top of the pile is subjected to an impulse force from the modal hammer, it can be seen that in addition to creating global bending in the pile (which is what we want to look at), there is also some localised three-dimensional distortion of the pile in the vicinity of the zone that experienced the impact. This distortion results in a localised vibration that is picked up by the accelerometers. The frequency of these localised vibrations is $86 \mathrm{~Hz}$ and $322 \mathrm{~Hz}$. Irrespective of the scour level being tested, the same two frequencies dominated the frequency spectrum, i.e. because they are local effects they are independent of scour depth. To further verify that the frequencies at $86 \mathrm{~Hz}$ and $322 \mathrm{~Hz}$ were due to local distortion/vibration of the pile, a $1.2 \mathrm{~m}$ long free-free section of pile was subjected to impact testing using the same modal hammer as was used in the field test. When the resulting acceleration signals were analysed, the frequency spectrum was again dominated by peaks at $86 \mathrm{~Hz}$ and $322 \mathrm{~Hz}$. 
In our analysis, we are interested in detecting the frequency peak corresponding to the first natural frequency of the pile and observing how this peak changes with scour. By treating the initial exposed length of pile as a rigid cantilever, we obtain an upper-bound value for the natural frequency of the pile analytically using the expression shown in Eq. (1). The initial exposed length is equal to $2.26 \mathrm{~m}$, which gives a first natural frequency of $63.8 \mathrm{~Hz}$. Therefore, for all scour depths, the natural frequency of the pile will be less than $63.8 \mathrm{~Hz}$. By focussing on the frequency spectrum below $63 \mathrm{~Hz}$, we can isolate the pile's first natural frequency. Fig. 6(c) shows a magnified view of the zone 0 to $63 \mathrm{~Hz}$ (of Fig. 6(b)) and we see a clear peak at $12.2 \mathrm{~Hz}$. This corresponds to the first natural frequency of the pile at Scour Level -4.

Once the frequency zone of interest has been defined by the upper-bound cantilever model, we can observe the change in the frequency spectra for different levels of scour. Fig. 7(a) shows a timehistory acceleration response obtained from Accelerometer 1 due to the applied impulse force, while testing at Scour Level -6 (see Fig. 5 for schematic). Fig. 7(b) displays the frequency content of the signal in Fig. 7(a) up to a maximum limit of $63.8 \mathrm{~Hz}$. Fig. 7(b) also displays the frequency content of the acceleration signal when the scour level was -4 . It can be seen that a reduction in natural frequency is observed with increased depth of scour.

(a)

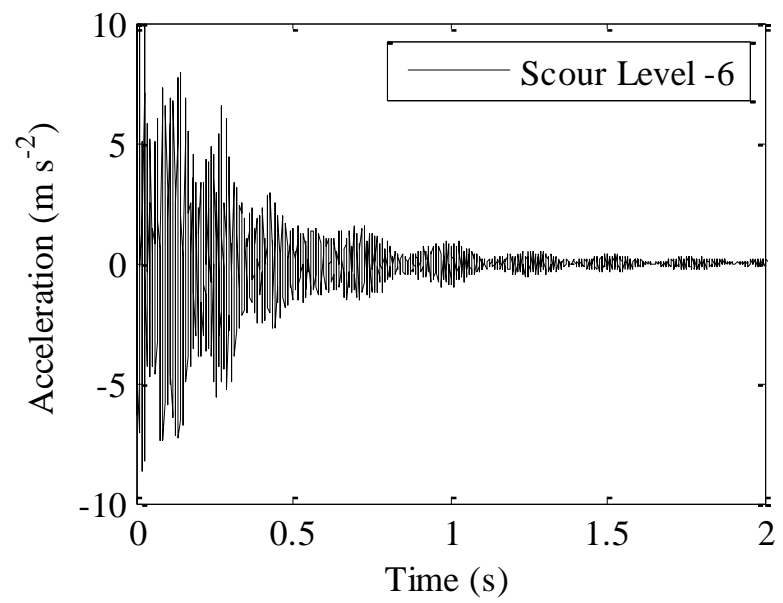

(b)

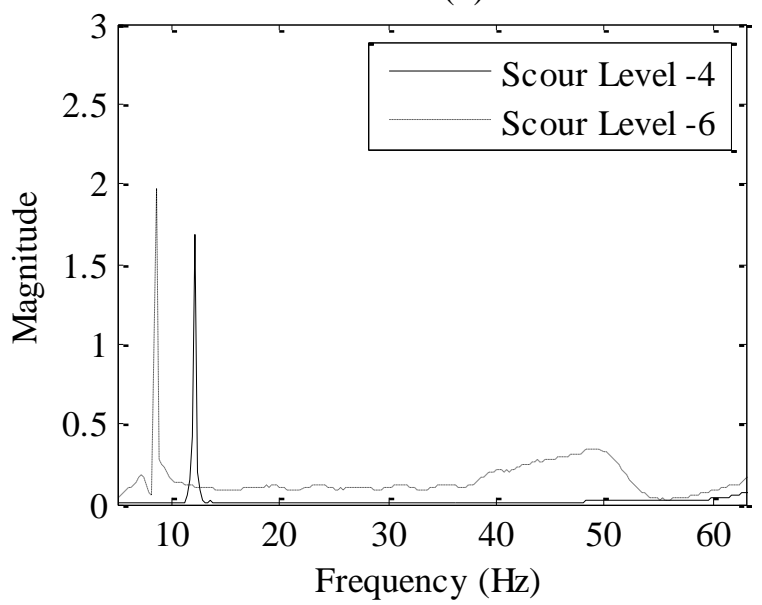

Fig. 7. Change in Frequency Content between two Scour Depths. (a) Scour Level -6 Acceleration Response $\left(\mathrm{m} \mathrm{s}^{-2}\right)$; (b) Frequency Spectra for Scour Levels -4 and -6

Fig. 8 shows the change in first natural frequency with increasing depth of scour. A gradual reduction in frequency is observed as scour depth increases. For completeness, the first natural frequency of an equivalent length rigid cantilever with the same geometric properties is also displayed in this figure. The cantilever results define the upper-bound threshold expected in the analysis. Our experimental results are in line with expectations, since all observed frequencies lie below the upper bound values. 
The photograph in Fig. 9 shows the experimental arrangement of the field test with scour testing at an advanced stage.

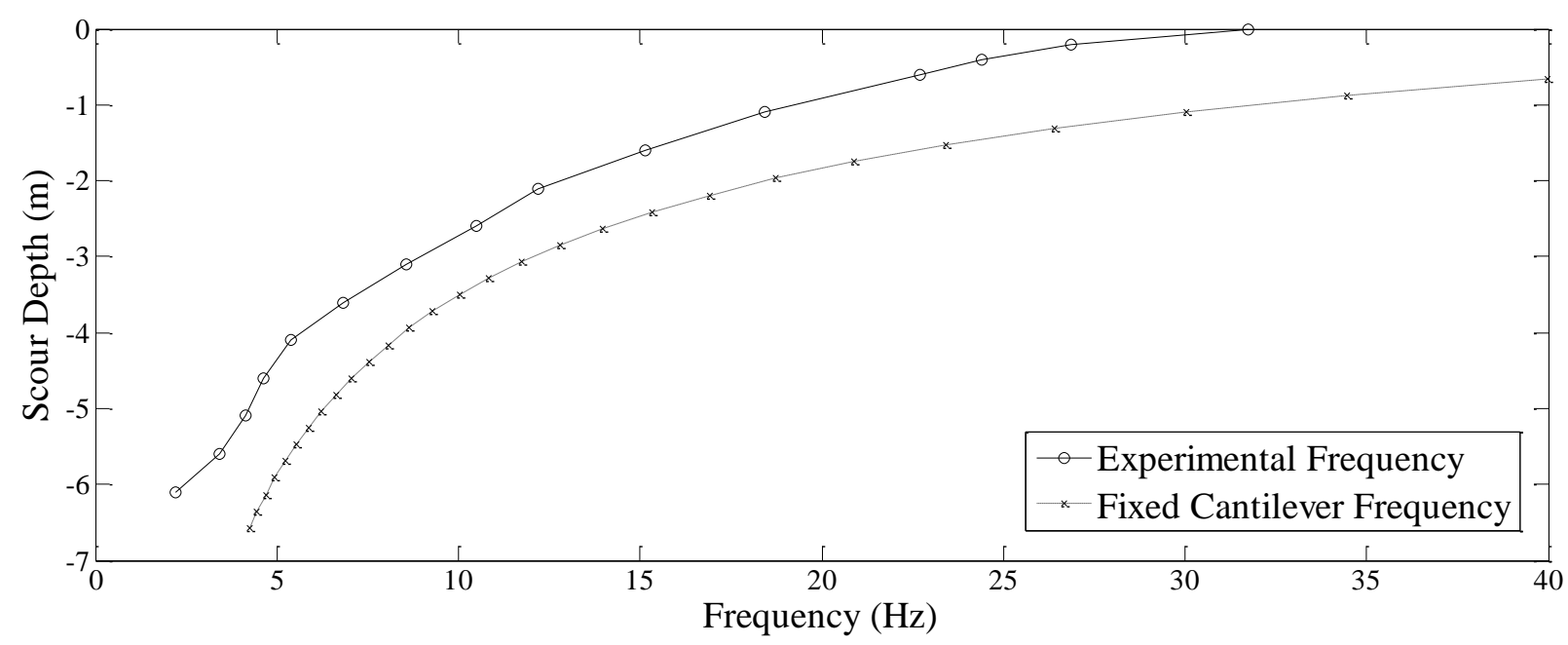

Fig. 8. Frequency Change with Scour Depth.

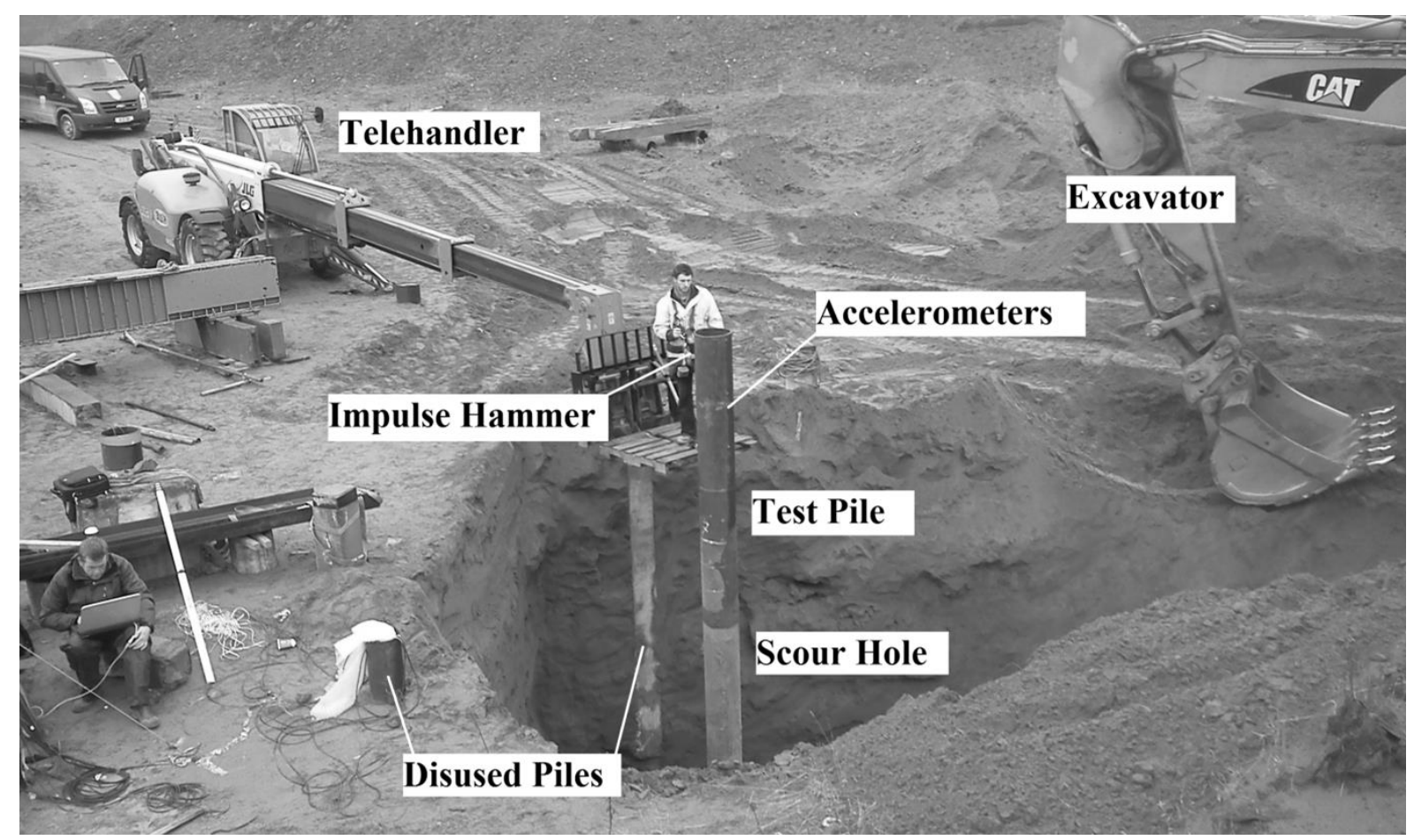

Fig. 9. Scour Test in Progress at Advanced Stage. 


\subsection{Theoretical}

It can be seen from the experimental response in Fig. 8 that a decrease in frequency may be observed as scour depth increases. However, it is the depth of scour that is often the parameter of interest, rather than the frequency value. If the soil-structure interaction could be modelled accurately, then it would be possible to obtain an indication of the severity of the scour problem by observing the natural frequency of the structure. To this end, a finite element model was developed in MATLAB to numerically simulate the laboratory and field tests. The structural model as well as the methods used to determine accurate geotechnical stiffness are described in the next section.

\subsection{Structural Model}

In the numerical simulations, the pile is modelled as being supported by a series of horizontal springs (see Figs. 10(b) and 11(b)). Referred to as the Winkler hypothesis [28], this method is known to yield reasonably good performance and is relatively straightforward to implement. The scour process is simulated by progressively removing the springs from the model commencing with those nearest the top. The exposed / embedded lengths at the commencement of the scour test for the laboratory and field piles are given in Figs. 10(a) and 11(a) respectively. The numerical models used to simulate the experimental and field piles are shown in Figs. 10(b) and 11(b) respectively.

The free end of the pile was modelled using standard four degree of freedom beam elements. The elemental stiffness and mass matrices for this kind of element are given in [29]. The embedded end of the pile was modelled using five degree of freedom spring-beam elements. The global stiffness and mass matrices for the structure were assembled in line with the procedure set out in [29]. The response of the discretised finite element model to a given impulse force is described by the dynamic equation of motion shown in Eq. (2).

$$
\left[\mathbf{M}_{\mathbf{G}}\right] \ddot{\mathbf{x}}_{\mathbf{p}}+\left[\mathbf{C}_{\mathbf{G}}\right] \dot{\mathbf{x}}_{\mathbf{p}}+\left[\mathbf{K}_{\mathbf{G}}\right] \mathbf{x}_{\mathbf{p}}=\mathbf{F}_{\mathbf{E x t}}
$$

Where $\mathbf{M}_{\mathbf{G}}, \mathbf{C}_{\mathbf{G}}$ and $\mathbf{K}_{\mathbf{G}}$ are the ( $\left.n \times{ } n\right)$ global mass, damping and stiffness matrices for the pile model respectively. The vector $\mathbf{x}_{\mathbf{p}}$ describes the displacement of each degree of freedom for a given time step. Similarly, the vectors $\dot{\mathbf{x}}_{\mathbf{p}}$ and $\ddot{\mathbf{x}}_{\mathbf{p}}$ describe the velocity and acceleration of each degree of freedom for a given time step. $\mathbf{F}_{\mathbf{E x t}}$ is a vector defining the external forces acting on each degree of freedom for a given time step. The impulse force in the model is applied to the transverse degree of freedom at the top of the pile.

Damping was modelled as Rayleigh damping, where the damping matrix is defined as a linear combination of the mass and stiffness matrices for the global system as shown in Eq. (3). 


$$
\left[\mathbf{C}_{\mathbf{G}}\right]=\alpha\left[\mathbf{M}_{\mathbf{G}}\right]+\beta\left[\mathbf{K}_{\mathbf{G}}\right]
$$

Where $\alpha=2 \xi \omega_{1} \omega_{2} /\left(\omega_{1}+\omega_{2}\right)$ and $\beta=2 \xi /\left(\omega_{1}+\omega_{2}\right) . \omega_{1}$ and $\omega_{2}$ are the first and second natural (circular) frequencies of the pile respectively and $\xi$ is the damping ratio of the system [30]. The damping ratio used in the model was the same as that calculated from the experimental data. The damping ratio was obtained using a relatively straightforward exponential curve fitting process [31].

The dynamic response of the system is calculated by solving the second order differential equation shown in Eq. (2). The equation is solved using numerical integration. The vectors $\mathbf{x}_{\mathbf{p}}, \dot{\mathbf{x}}_{\mathbf{p}}$, and $\ddot{\mathbf{x}}_{\mathbf{p}}$ are determined for each time step. The integration scheme used was the Wilson-Theta Method as given in [32]. A value of $\theta=1.4$ was chosen for the integration scheme as this provides unconditional stability in the model [33]. An analysis to calculate the system eigenvalues, which correspond to the natural frequencies and the eigenvectors, which correspond to the mode shapes, was also carried out.

In order to check the numerical model and ensure its correct operation, the static displacements, natural frequencies and mode shapes predicted by the model were checked against those predicted by the commercial finite element package PATRAN. Good agreement between both models was observed. 


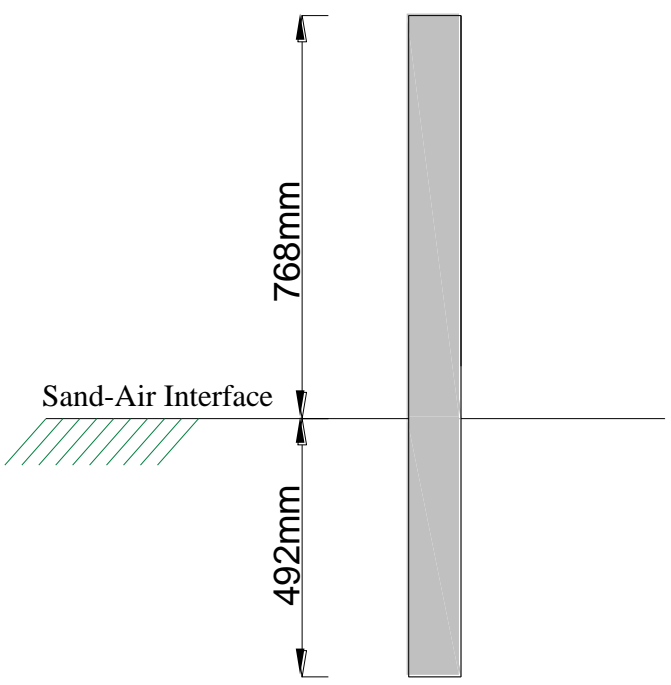

(a)

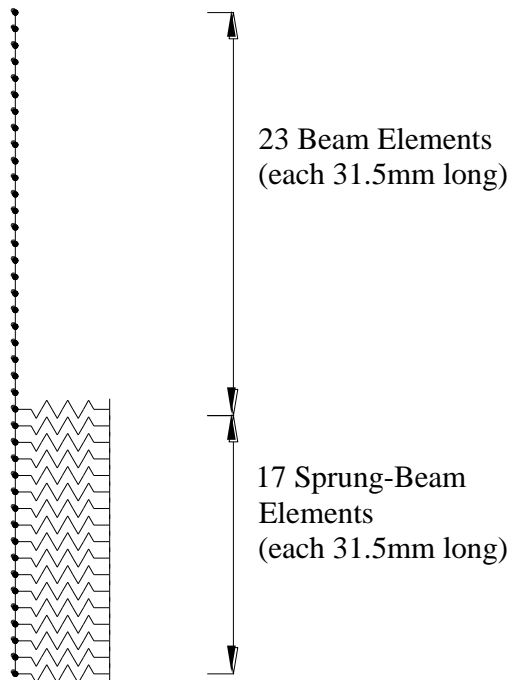

(b)

Fig. 10. Numerical Model to Simulate Laboratory Test. (a) Geometry at start of scour test; (b) Numerical model corresponding to dimensions shown in (a).

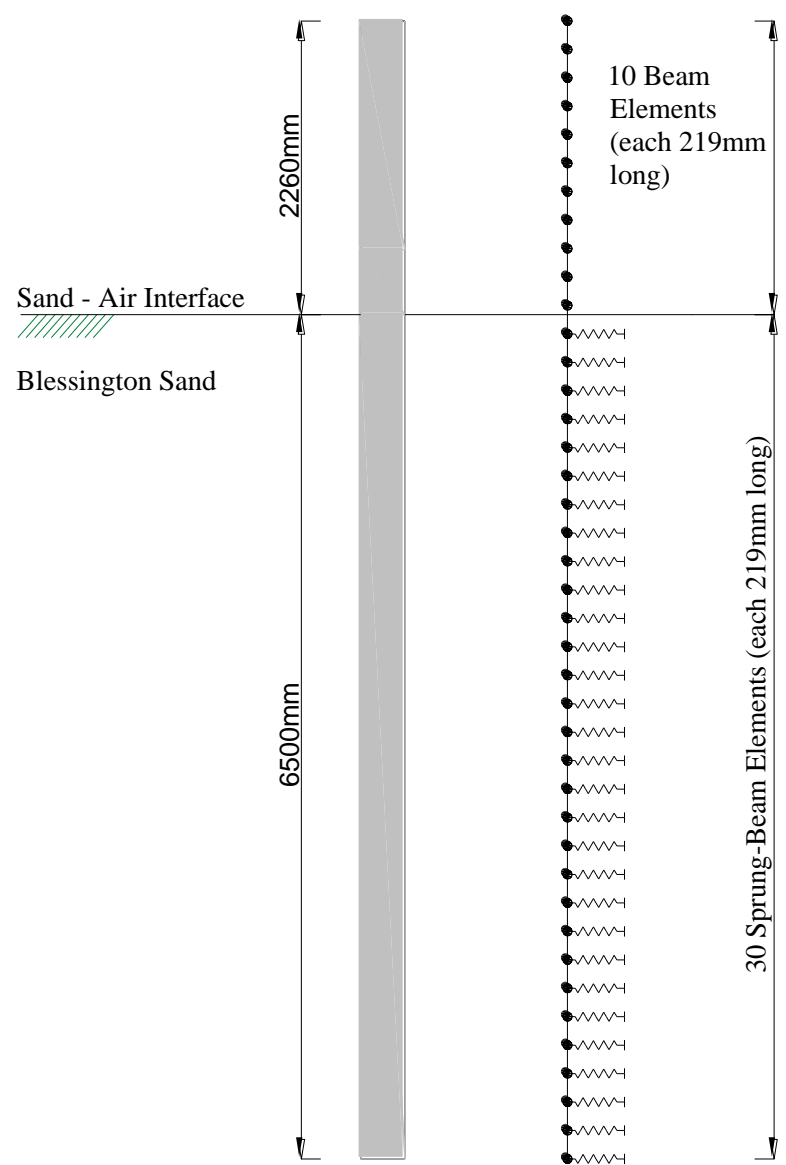

(a)

(b)

Fig. 11. Numerical Model to Simulate Field Test. (a) Geometry at start of scour test; (b) Numerical model corresponding to dimensions shown in (a). 


\subsection{Geotechnical Stiffness Determination}

For the numerical model to correctly simulate the observed behaviour of the laboratory or field piles, it is crucial that the stiffness assigned to the springs accurately reflects the lateral stiffness of the sand around the pile. In this paper, two methods are considered to model lateral spring stiffness values.

The first method uses the small-strain stiffness values measured directly or indirectly at the site. Direct measurements of the small-strain shear modulus $\left(\mathrm{G}_{0}\right)$ were derived from shear wave velocity measurements made using the MASW technique. For sites where MASW measurements are not available the use of indirect measures of small-strain stiffness were considered, in this instance linking $\mathrm{G}_{0}$ and $\mathrm{q}_{\mathrm{c}}$. The rigidity index (ratio of small-strain shear modulus to strength) is a useful index in terms of soil classification. For a given deposit $\mathrm{G}_{0} / \mathrm{q}_{\mathrm{c}}$ increases with sand age and cementation [27]. The variation of $\mathrm{G}_{0} / \mathrm{q}_{\mathrm{c}}$ with $\mathrm{q}_{\mathrm{c} 1}$ for a range of sands was examined by [26, 27, 34] and others. For an aged, over-consolidated material at the stress levels present at the test site, a rigidity index in the range 5 to 8 is expected. In our analysis we assumed a value of 6 .

The second method utilises spring stiffness proposed in a widely employed design code for laterally loaded piles, the American Petroleum Institute (API) method. The laboratory test was modelled using the API method only as no shear wave or CPT data was available for this test. The results of both methods are presented in section 4.0. Spring stiffness values calculated in this study are referred to as $\mathrm{k}_{\mathrm{s}}$.

\subsubsection{Method 1 - Small-Strain Stiffness $\left(G_{0}\right)$}

The stiffness of soils is strain level dependent [35]. Since dynamic loading imparts very small strains in a soil mass, the small-strain shear modulus $\left(\mathrm{G}_{0}\right)$ is a particularly useful parameter for dynamic analyses. $\mathrm{G}_{0}$ is controlled by the in-situ soil state (density and stress level) and also by the effects of ageing and cementation. Therefore, it is relatively difficult to predict. However, $\mathrm{G}_{0}$ values can be measured using reliable and relatively low cost in-situ geophysical techniques such as the MASW method. It is also possible to correlate a $\mathrm{G}_{0}$ value from in-situ measured CPT $\mathrm{q}_{\mathrm{c}}$ values [27]. The shear modulus $\left(\mathrm{G}_{0}\right)$, which varies with depth, can be converted to equivalent lateral spring stiffness $\left(\mathrm{k}_{\mathrm{s}}\right)$ values at discrete locations along the pile shaft (see Fig. 4(c) for $G_{0}$ profile derived from both the MASW method and CPT data). The first stage involves converting the $G_{0}$ profile to a Young's modulus $\left(\mathrm{E}_{0}\right)$ profile, using an appropriate small-strain Poisson's ratio (v) as shown in Eq. (4).

$$
E_{0}=2 G_{0}(1+v)
$$

The $\mathrm{E}_{0}$ profile may be converted to a modulus of Subgrade Reaction $(\mathrm{K})$ profile. The modulus of Subgrade Reaction $(\mathrm{K})$ for the sand-pile interface is derived using Eq. (5), which provides a relationship between the modulus of Subgrade Reaction (of the sand) and the material properties of the pile in the elastic continuum [36]. 


$$
K=\frac{1.0 E_{0}}{1-v^{2}}\left[\frac{E_{0} D^{4}}{E_{p} I_{p}}\right]^{1 / 12}
$$

where $\mathrm{D}=$ pile diameter $(\mathrm{m}) ; \mathrm{E}_{\mathrm{p}}=$ Young's modulus of steel $\left(\mathrm{kN} \mathrm{m}^{-2}\right) ; \mathrm{I}_{\mathrm{p}}=$ moment of inertia of pile cross-section $\left(\mathrm{m}^{4}\right)$. The individual spring stiffness values $\left(\mathrm{k}_{\mathrm{s}}\right)$ may be calculated by multiplying the modulus of Subgrade Reaction (K) at any particular depth by the soil spring spacing (x) (see Fig. 11(b)).

\subsubsection{Method 2 - API Design Code}

In geotechnical engineering practice, the analysis of laterally loaded piles is routinely based on a Winkler model in which the pile-soil interaction problem is equivalent to a beam supported by a series of uncoupled springs. The principle of using soil springs to represent the soil reaction is illustrated in Fig. 12. The lateral force (p) against lateral displacement (y) response to a set of external loads (Vertical (V), Horizontal (H) and Moment (M)) can be represented by a linear or non-linear curve. The curve describes the soil reaction $(\mathrm{p})$ at a given depth as a function of the lateral movement $(\mathrm{y})$. The spring stiffness $\left(\mathrm{E}_{\mathrm{py}}\right)$ is defined as the secant modulus of the p-y curve (see Fig. 12). The approach is formulated in design methods including the American Petroleum Institute, API (2007) code [37].
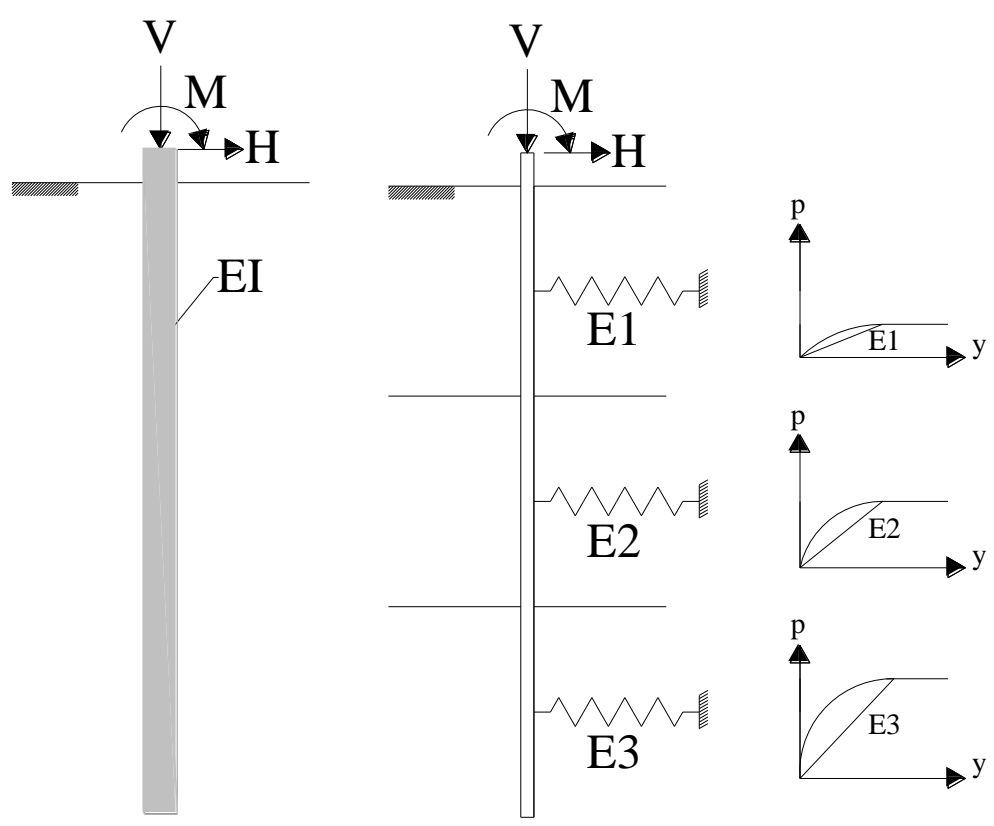

Fig. 12 Winkler approach and definition of p-y curves [38]

The application of the Winker approach for laterally loaded piles was first suggested by [39]. In [40], a database of fourteen lateral load tests was compiled and a hyperbolic model to predict the pile 
response was proposed, which has been incorporated into the current API design method as shown in Eq. (6).

$$
p=A p_{u} \tanh \left(\frac{k x}{A p_{u}} y\right)
$$

where $\mathrm{p}_{\mathrm{u}}=$ ultimate lateral resistance at depth ' $\mathrm{x}$ ' below the surface $\left(\mathrm{kN} \mathrm{m}^{-1}\right), \mathrm{k}=$ initial modulus of subgrade reaction $\left(\mathrm{kN} \mathrm{m}^{-3}\right), \mathrm{A}=$ empirical factor accounting for static or cyclic loading conditions, $\mathrm{y}=$ lateral deflection $(\mathrm{m})$. Values of $\mathrm{k}$ which depend on the soil density (or friction angle) are given in the API design code, although $\mathrm{k}$ is assumed to be constant for relative densities above $80 \%$, or for friction angles above $39^{\circ}$ [37].

Eq. (6) allows for the existence of non-linear spring stiffness over a relatively large range of displacements up to failure, since the stiffness is defined as the secant modulus of the non-linear p-y curve. However, in our analysis, the application of an impulse force to dynamically excite the pile mobilises only very small strains in the sand mass. By differentiating Eq. (6) with respect to ' $y$ ', the initial (small-strain) stiffness in the p-y curve can be determined [41, 42]. This is shown in Eq. (7).

$$
\left.\frac{\mathrm{d} p}{\mathrm{~d} y}\right|_{y=0}=\left.A p_{u} \frac{\frac{k x}{A p_{u}}}{\cosh ^{2}\left(\frac{k x y}{A p_{u}}\right)}\right|_{y=0}=k x
$$

Discrete spring stiffness values $\left(\mathrm{k}_{\mathrm{s}}\right)$ along the pile shaft are obtained by multiplying the small-strain stiffness modulus term in Eq. (7) ( $k x)$ by the spacing between springs, at each depth.

The stiffness profiles derived using the small-strain shear modulus $\left(\mathrm{G}_{0}\right)$ from the MASW and CPT testing as well as that derived from the API method are shown in Fig. 13. 


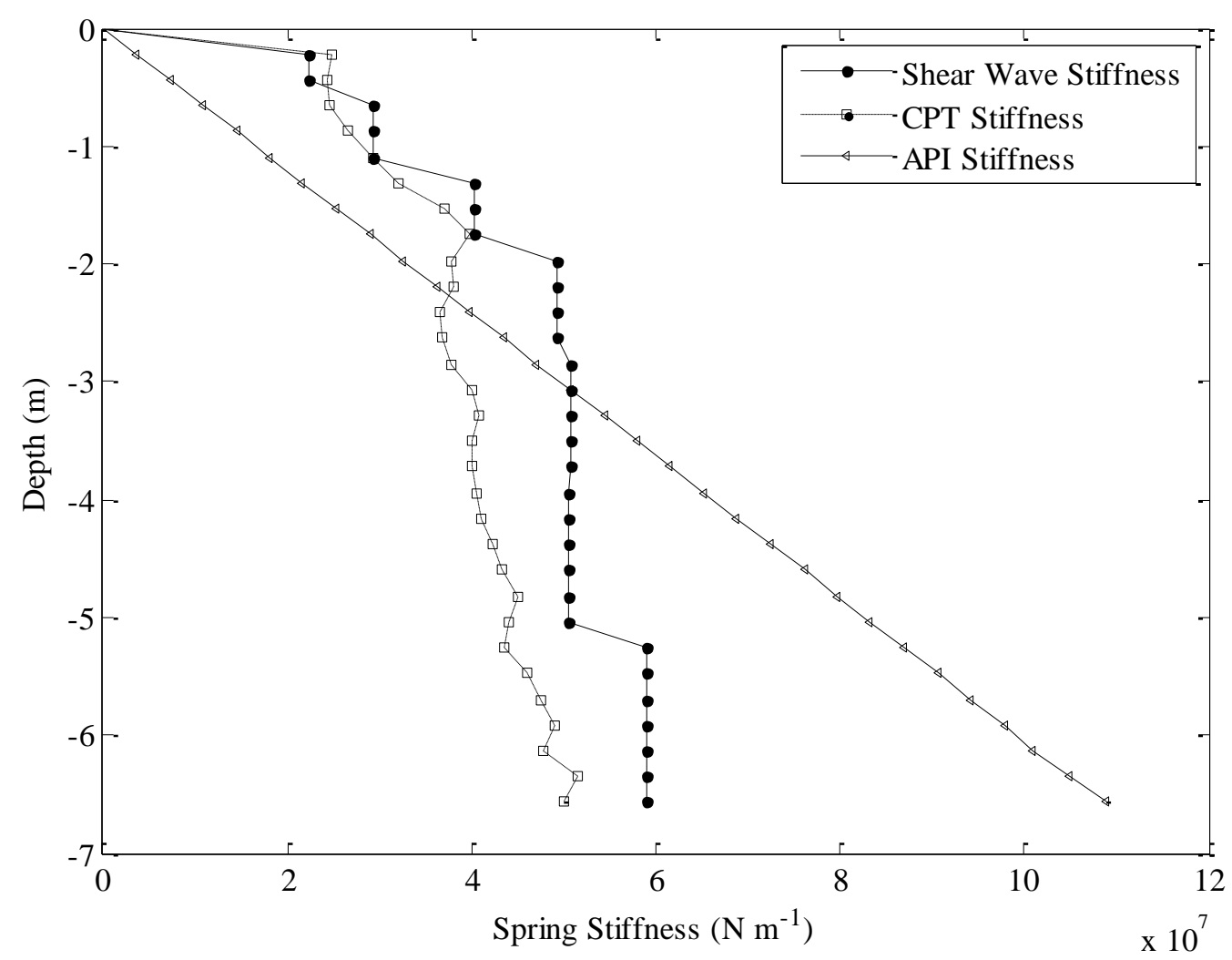

Fig. 13. Spring Stiffness Profiles for Blessington Site $\left(\mathrm{N} \mathrm{m}^{-1}\right)$.

\subsection{Results of Laboratory Test, Field Trial and Numerical Simulations}

\subsection{Numerical Model of Laboratory Pile}

When modelling the laboratory pile numerically, the spring stiffness values used in the model were calculated using the API method, as no $\mathrm{G}_{0}$ data was available for the small scale experiment. Figs. 14(a) and 14(b) present the experimental and numerical acceleration signals for Scour Levels A and E respectively, (Fig. 1 shows a diagram of scour levels). The solid line in Fig. 14(a) shows the acceleration response at Scour Level A when the laboratory pile was subject to an impact force, the dashed line shows the acceleration response predicted by the numerical model. Fig. 14(b) presents similar data for Scour Level E. It can be seen in Figs. 14(a) and 14(b) that the acceleration signal predicted by the numerical model does not match well with the acceleration signal observed experimentally. Fig. 14(c) shows the frequency content of the signals shown in Figs. 14(a) and 14(b). For clarity, the magnitudes of the numerical and experimental signals are plotted on the y-axes to the left and right of the figure respectively. It can be seen in Fig. 14(c) that the frequency of the signals generated numerically are well below the frequencies observed experimentally. However, the numerical signals do show a reduction in frequency between Scour Levels A and E. The solid and dashed lines in Fig. 14(d) respectively show the change in frequency with increasing scour depth for 
the experimental test and the numerical simulation. It is evident from Fig. 14(d) that the numerical model is not correctly simulating the behaviour of the laboratory pile. Firstly, the frequencies observed in the numerical signals are far lower than those determined experimentally. Secondly, although the numerical model identifies some reduction in frequency with increasing scour depth, the fall off is much less pronounced than observed in experimental signals.

(a)
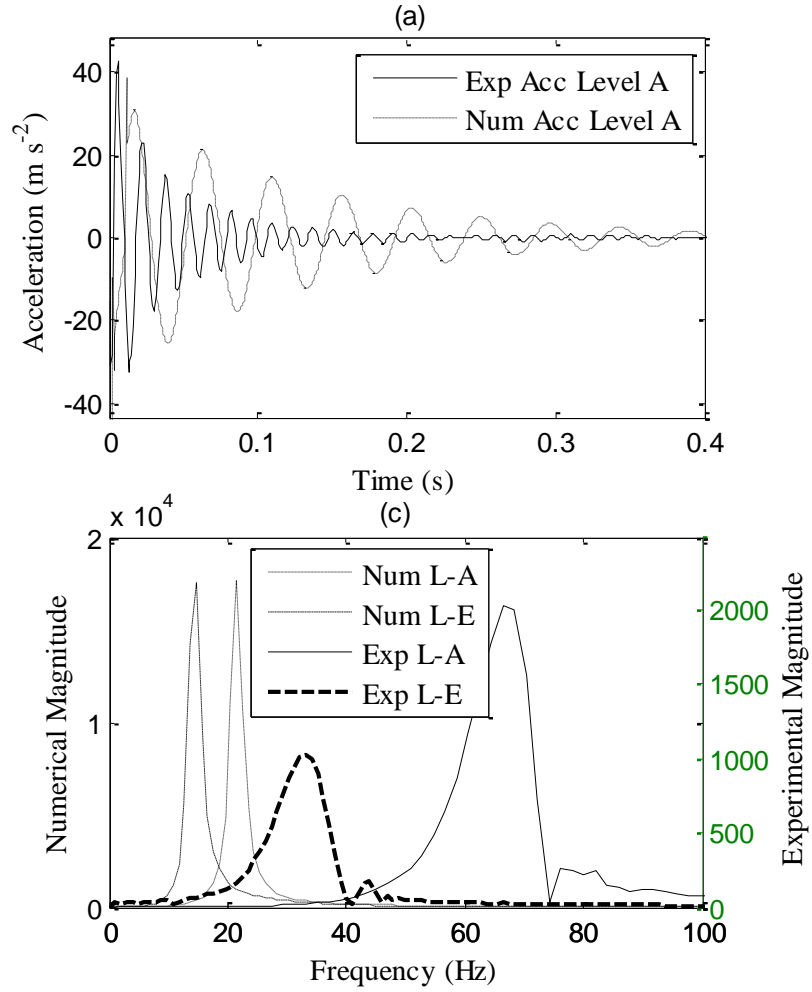

(b)

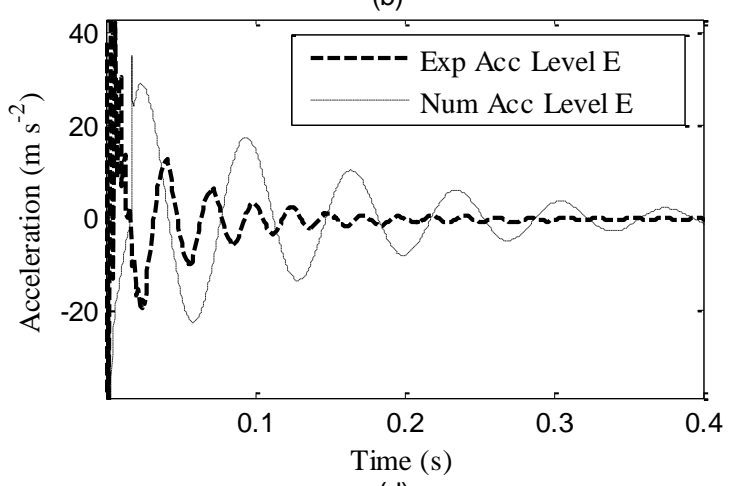

(d)

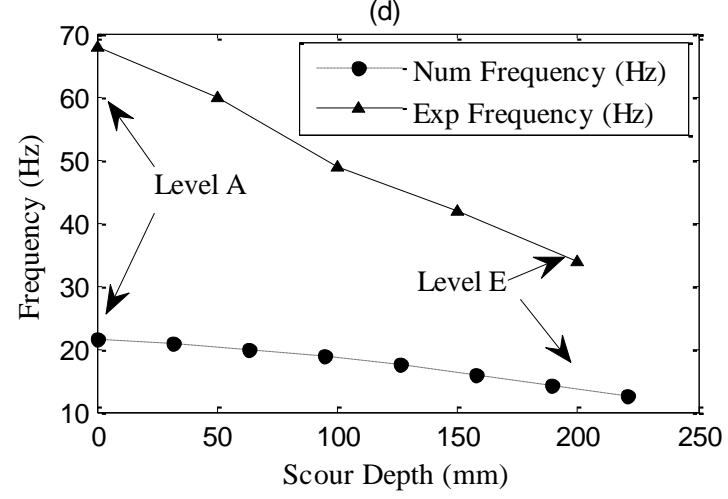

Fig. 14. Theoretical and Experimental Results for Laboratory Test. (a) Experimental + Numerical Acceleration Signal for Scour Level A; (b) Experimental + Numerical Acceleration Signal for Scour Level E; (c) Frequency Content of Signals; (d) Frequency Change with Scour Depth.

The error in the numerical model is due to the fact that the stiffness of the springs used in the model are too low, and as a result the numerical model is underestimating the natural frequency of the system. The API method is regarded as quite conservative and can underestimate in-situ stiffness, particularly in the case of stiff piles $[43,44]$. So, some underestimation of sand stiffness is to be expected. However, in the view of the authors, one particular aspect of the laboratory experiment is causing the API method to substantially underestimate the stiffness of the sand around the laboratory pile. The in-situ stiffness of soil depends on the sand density and mean stress level, where mean stress is the sum of the vertical stress and twice the horizontal stress [45]. The sand used in the model was compacted into the mould in lifts of $100 \mathrm{~mm}$, leading to the generation of high lateral stresses and high in-situ density. As a result of this compaction mechanism, the mean stress profile in the sample would be relatively uniform, with perhaps some surface effects. As such, a uniform stiffness profile 
for the model may be more appropriate. In order to improve the accuracy of the numerical model, the spring stiffness values were increased from the API values to a uniform stiffness of $5 \times 10^{6} \mathrm{~N} \mathrm{~m}^{-1}$ (see Fig. 15).

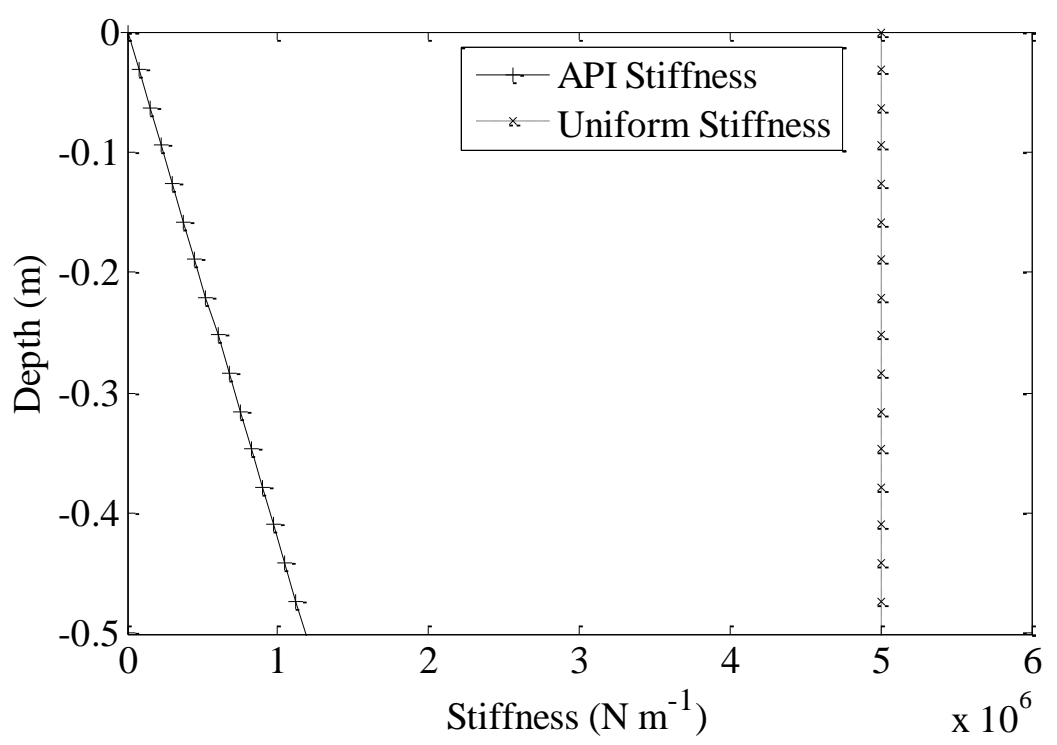

Fig. 15. Stiffness Profiles for the Laboratory Pile used in the Numerical Model.

The solid line in Fig. 15 shows the spring stiffness values prescribed by the API approach. These were the spring stiffness constants used in the model that generated the numerical acceleration signals shown in Figs. 14(a) and 14(b). The dashed line in Fig. 15 shows the spring stiffness used in the model that generated the numerical acceleration signals shown in Figs. 16(a) and 16(b). In Fig. 16(a) and 16(b), it can be seen that there is good agreement between the signals generated numerically and those observed experimentally for two different scour levels.

The solid and dashed lines in Fig. 16(c) respectively show the change in frequency with increasing scour depth for the experimental test and the revised numerical simulation. Unlike Fig. 14(d), this time the frequency changes predicted by the numerical model provide a good match with those observed experimentally. The plots in Fig. 16 demonstrate that if accurate values of spring stiffness are used, it is feasible to numerically model the change in frequency with increasing scour depth. Therefore, a numerical model could be used to estimate scour depths on a pile, i.e. you match the frequency observed in the field with the scour depth corresponding to this frequency in the numerical model. 
(a)
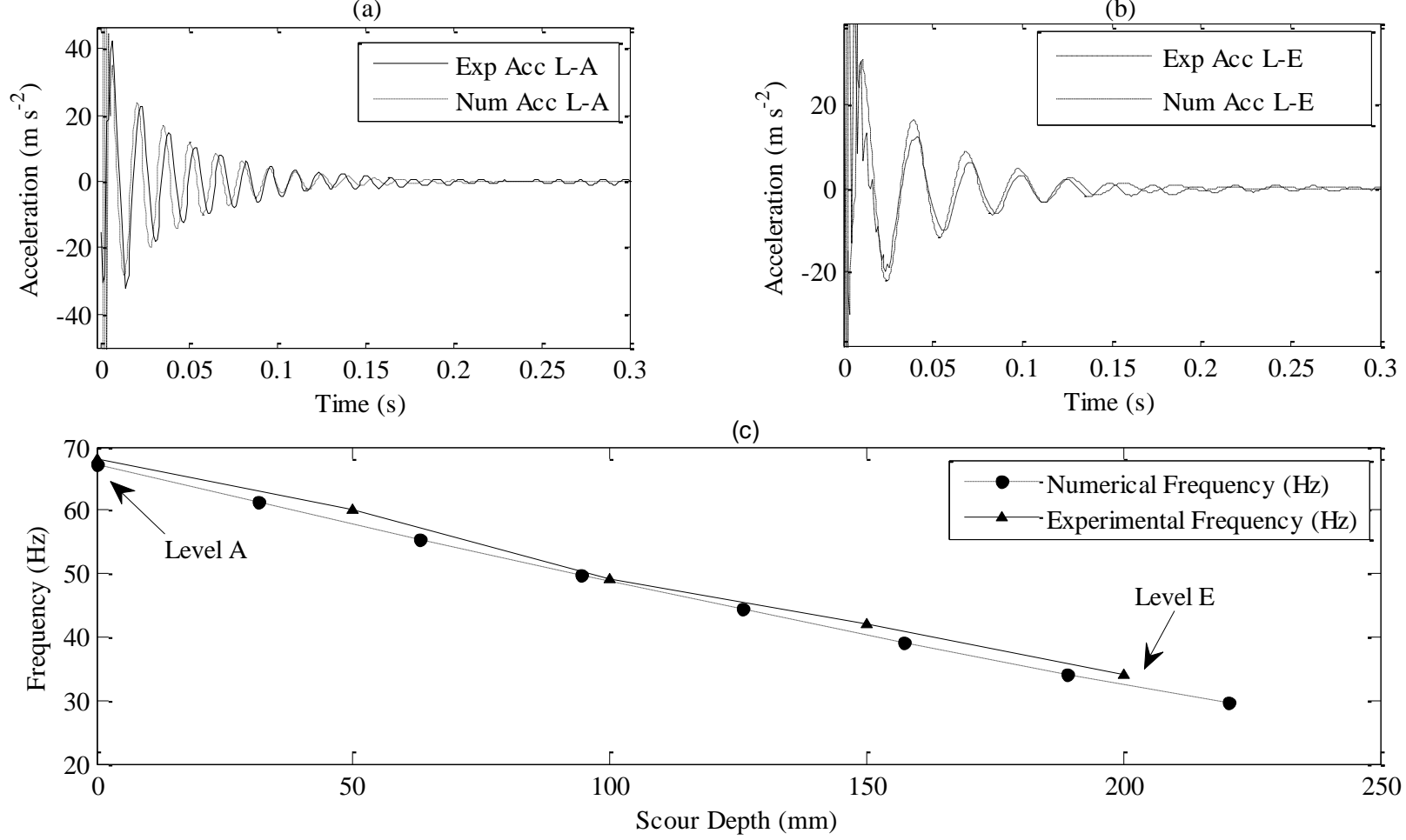

(b)

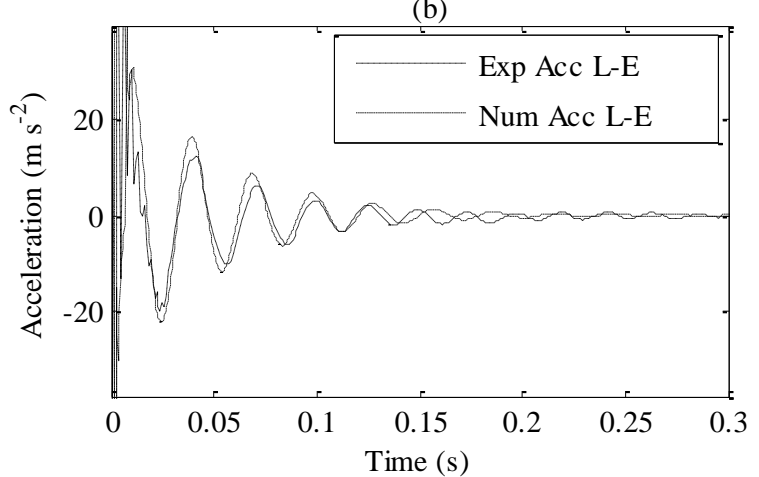

c

\section{.}

.


(a)

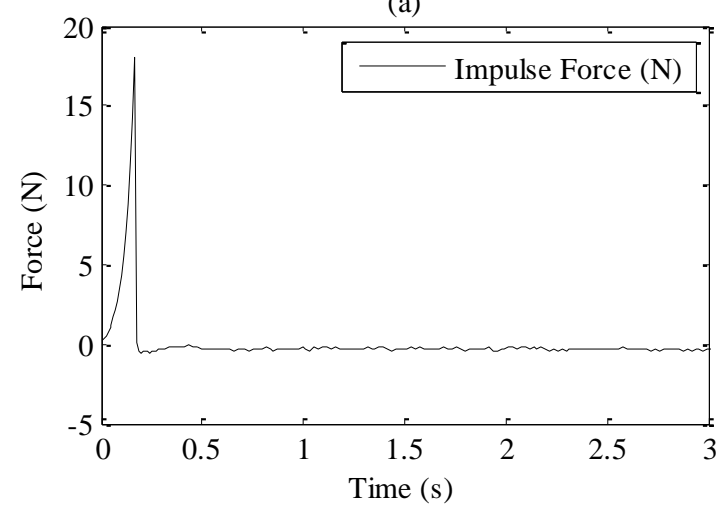

(b)

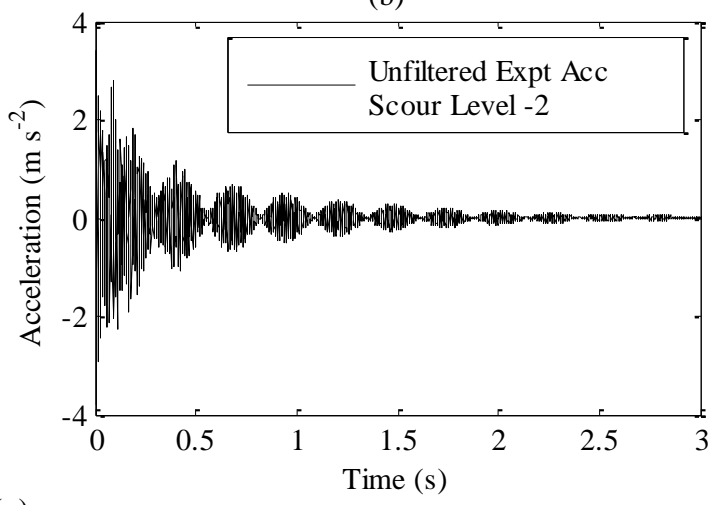

(c)

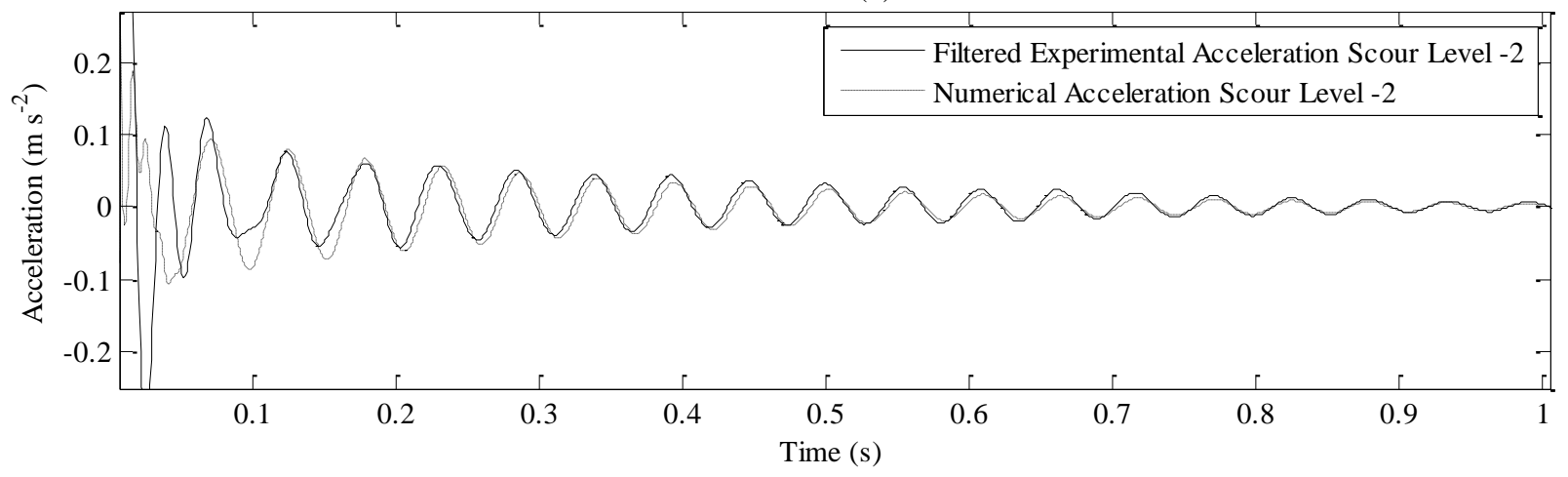

Fig. 17. Theoretical and Experimental Results for Field Test. (a) Impulse Force applied to top of Pile (N); (b) Unfiltered Acceleration Signal at Scour Level -2 ( $\mathrm{m} \mathrm{s}^{-2}$ ); (c) Filtered Signal compared with Numerical Model at Scour Level $-2\left(\mathrm{~m} \mathrm{~s}^{-2}\right)$.

Fig. 17(a) shows the impulse force applied to the top of the pile while testing at Scour Level -2, measured using the modal hammer. Fig. 17(b) shows the experimental acceleration response from Accelerometer 1, due to the impulse force in Fig. 17(a). This acceleration response contains a significant amount of high frequency vibration (> $63.8 \mathrm{~Hz}$ ), which is due to local effects in the pile generated during the testing regime (see section 2.2). We did not aim to get our model to match the signal shown in Fig. 17(b) because much of the high frequency oscillations (> $63 \mathrm{~Hz}$ ) evident in the signal are local effects and are therefore not relevant to the global issue of trying to identify scour.

(Incidentally, if one wanted to get the numerical results to match the signal shown in Fig. 17(b) it would be necessary to use a numerically intensive 3D finite element model to simulate the distortion of the pile in the vicinity of the zone that experienced the impact). Instead, the authors show that if a low pass filter (cut-off frequency $63 \mathrm{~Hz}$ ) is applied to the acceleration signal in Fig. 17(b), the solid plot in Fig. 17(c) results. The application of the low pass filter has the effect of exposing the portion of the acceleration signal pertaining to the transverse bending of the pile. When the impulse force in Fig. 17(a) was applied in the numerical model, the dashed plot in Fig. 17(c) results. The unsteady response in the initial portion of both the experimental and numerical signals in Fig. 17(c), up to a value of approximately 0.1 seconds, is due to the duration of application of the impulse load. A similar study of this phenomenon is available in [46]. The numerical results presented in Fig. 17(c) 
were simulated using the spring stiffness values derived from $\mathrm{G}_{0}$ obtained from shear wave velocity measurements, (see Fig. 13 for exact spring stiffness values). The plots in Fig. 17(c) prove that the numerical model is simulating very accurately the transverse bending of the pile. Therefore, the use of $\mathrm{G}_{0}$ values to approximate spring stiffness is quite good for dynamic applications.

Fig. 18 charts the drop in frequency with increasing scour depth and it shows that the frequencies predicted by the numerical models using $\mathrm{G}_{0}$ derived stiffness (namely the shear wave velocity and CPT profiles) agreed well with those observed experimentally across the range of scour depths tested. The numerical model developed using stiffness derived from the API design code showed a tendency to underestimate the frequency response for low depths of scour and overestimate slightly at higher depths of scour. It is also noteworthy that for a pile with a different geometry (longer penetration depth), the API method would overestimate the frequency response at higher scour depths significantly due to its linearly increasing stiffness profile with depth. Overall it was found that the experimentally measured first natural frequency drops from an initial value of $33 \mathrm{~Hz}$ for the case of zero scour to approximately $2 \mathrm{~Hz}$ for a scour depth of $6 \mathrm{~m}$.

As a checking tool, at each scour level the frequency of an equivalent cantilever is calculated analytically and the results are plotted using ' $x$ ' data markers in Fig. 18. As expected, for all scour depths, the frequencies observed experimentally are lower than the frequency of an equivalent cantilever, i.e. the cantilever results provide an upper-bound value in the analysis. Fig. 18 shows that the models using stiffness derived from the small-strain shear modulus $\left(G_{0}\right)$, obtained from in-situ MASW and CPT testing could be used to provide a relatively accurate estimate of scour depth for a given observed frequency.

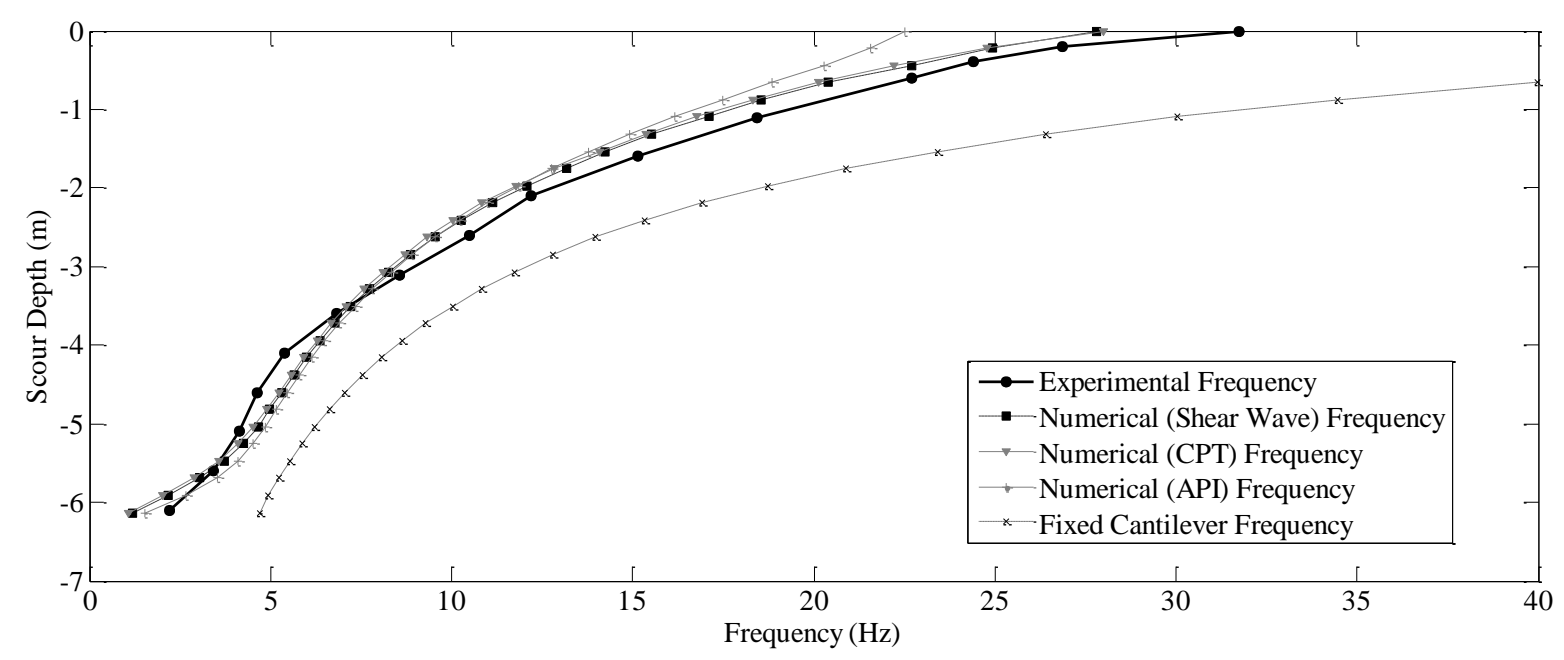

Fig. 18. Frequency Change with Scour showing Experimental Response, Numerical Response and Analytical Upper-Bound Equivalent Cantilever. 


\subsection{Conclusion}

This paper has shown that it is possible to detect the presence of scour by monitoring the natural frequency of a pile, and moreover that the depth of scour can be estimated from the observed frequency.

Initially, a laboratory experiment to simulate pile scour was undertaken. In this test, a model pile was installed in a sand matrix in a steel mould and was instrumented with an accelerometer. The top layer of sand was progressively removed to simulate scour. At each scour level, the pile was subjected to transverse impact loading and the resulting acceleration signal was recorded. Fourier transforms were used to calculate the dominant frequency at each scour level and it was found that there was a clear reduction in frequency with increasing scour depth.

Subsequently, a similar approach was used to test a pile in the field. Unlike the laboratory acceleration signals, the field acceleration signals contained many frequencies and initially were more difficult to interpret. However, by regarding the initial exposed length of the pile as the effective length of an equivalent cantilever, it was possible to calculate an upper bound frequency. Therefore, tracking the change in frequency with increasing scour was simply a matter of examining the frequency spectra between $0 \mathrm{~Hz}$ and the upper bound value. Similar to the laboratory tests, it was found that the natural frequency was inversely proportional to the scour depth.

In reality, being able to track the change in frequency of a bridge pile is of limited use to the structure owner especially if that frequency cannot be correlated to a scour depth. However, if the observed frequency could be used to estimate a scour depth, this would support more informed decision making. To that end, a spring-beam finite element model of the sand-pile system was developed in order to establish whether a correlation between observed frequency and scour depth was possible. Obviously, for the model to be effective it is crucial that the spring stiffness values used in the model accurately reflect the stiffness at the sand-pile interface. Two recognised geotechnical methods were used to calculate the spring stiffness; the first method used values derived from in-situ $\mathrm{G}_{0}$ data obtained from the MASW method and a correlation to the CPT $\mathrm{q}_{\mathrm{c}}$ value. The second method used stiffness derived from the API design code. The results from both methods were fed into the development of separate numerical models. It was found that the frequencies predicted by the numerical models using $\mathrm{G}_{0}$ derived stiffness (for a given scour depth) agreed well with the frequencies observed experimentally. The API method, however, did underestimate the frequency response for low depths of scour. The response predicted by the API method would also be very sensitive to the depth of pile penetration with longer penetration depths resulting in an over-estimation of stiffness at depth. It is therefore not recommended to use the API method to derive stiffness profiles for the purpose of scour depth estimation. The analyses showed that by using appropriate geotechnical techniques and numerical modelling approaches, the sand-pile system could be modelled 
accurately. Once the system is modelled correctly, it is possible to correlate observed frequency with scour depth and thereby provide decision support to the structure owner.

The novelty in this paper is the development of a method that uses the actual structural response to indicate the severity of the problem, with excitation by means of traffic loading on the structure. Any distress felt by the structure as a result of scour will be indicated in its dynamic response and picked up by accelerometers as a change in frequency. Other sensors that are placed near bridge foundations may not necessarily capture the scour effect on the structure as only the scour hole local to the sensor will be captured. Although the sensor may be placed near the problem area, the global effect of scour on the structure may still be missed. In the present study, the global effect of scour is captured as a change in the response of the pile foundation itself, which is a novel approach. The applications of the methods developed herein extend beyond scour detection. Any stiffness degradation in the foundation due to excessive cyclic loading may also be captured as a change in dynamic characteristics by accelerometers placed on the structure. This is due to the fact that the stiffness of soil is strain-level dependant and any excessive loading may reduce the foundation stiffness, which could be detrimental to the carrying capacity of the foundation elements. Accelerometers allow for direct measurement of structural distress.

The study presented in this paper deals with the development of the concepts required to estimate the depth of scour based on an observed natural frequency of a single pile. Further research is required to apply these concepts to the monitoring of full-scale real structures, due to the complexity of the interactions at this scale. The current study serves as a preliminary investigation in this regard. 


\section{Acknowledgements}

The authors would like to acknowledge the support of the Earth and Natural Sciences (ENS) Doctoral Studies Programme, funded by the Higher Education Authority (HEA) through the Programme for Research at Third Level Institutions, Cycle 5 (PRTLI-5), co-funded by the European Regional Development Fund (ERDF) and the European Union Framework 7 project SMART RAIL (Project No. 285683). 


\section{References}

[1] L.Hamill, Bridge Hydraulics, E.\& F.N. Spon, London, 1999.

[2] L.C.Bolduc, P.Gardoni, J.L.Briaud, Probability of Exceedance Estimates for Scour Depth around Bridge Piers. Journal of Geotechnical and Geoenvironmental Engineering 134 (2008) 175-185. doi: 10.1061/(ASCE)1090-0241(2008)134:2(175)

[3] K.Wardhana, F.C.Hadipriono, Analysis of Recent Bridge Failures in the United States. Journal of Performance of Constructed Facilities 17 (2003) 144-151. doi:10.1061(ASCE)08873828(2003)17:3(144)

[4] F.N.Catbas, M.Susoy, and D.M.Frangopol, Structural health monitoring and reliability estimation: Long span truss bridge application with environmental monitoring data. Engineering Structures 30 (2008) 2347-2359. doi:10.1016/j.engstruct.2008.01.013

[5] R.W.P.May, J.C.Ackers, and A.M.Kirby, Manual on scour at bridges and other hydraulic structures, London, 2002.

[6] M.Heidarpour, H.Afzalimehr, E.Izadinia, Reduction of local scour around bridge pier groups using collars. International Journal of Sediment Research 25 (2010) 411-422. doi:10.1016/S1001-6279(11)60008-5

[7] M.C.Forde, D.M.McCann, M.R.Clark, K.J.Broughton, P.J.Fenning, A.Brown, Radar measurement of bridge scour. NDT\&E International 32 (1999) 481-492.

[8] F.De Falco, R.Mele, The monitoring of bridges for scour by sonar and sedimetri. NDT\&E International, 35 (2002) 117-123.

[9] NCHRP, Monitoring Scour Critical Bridges - A Synthesis of Highway Practice, Washington, DC, 2009.

[10] J.L.Briaud, S.Hurlebaus, K.Chang, C.Yao, H.Sharma, O.Yu, C.Darby, B.E.Hunt, and G.R.Price, Realtime monitoring of bridge scour using remote monitoring technology, Austin, TX, 2011.

[11] N.Yankielun, L.Zabilansky, Laboratory Investigation of Time-Domain Reflectometry System for Monitoring Bridge Scour. Journal of Hydraulic Engineering 125 (1999) 1279-1284.

[12] E.A.Hussein, Vibration Based Damage Detection of Scour in Coastal Bridges, PhD Thesis, North Carolina State University, 2012.

[13] N.L.Anderson, A.M.Ismael, T.Thitimakorn, Ground-Penetrating Radar: A Tool for Monitoring Bridge Scour. Environmental \& Engineering Geoscience 13 (2007) 1-10.

[14] A.Zarafshan, A.Iranmanesh, F.Ansari, Vibration-Based Method and Sensor for Monitoring of Bridge Scour. Journal Of Bridge Engineering 17 (2012) 829-838. doi:10.1061/(ASCE)BE.1943-5592.0000362.

[15] S.Foti, D.Sabia, Influence of Foundation Scour on the Dynamic Response of an Existing Bridge. Journal Of Bridge Engineering 16 (2011) 295-304. doi:10.1061/(ASCE)BE.19435592.0000146.

[16] H.Sohn, Effects of environmental and operational variability on structural health monitoring. Philosophical transactions. Series A, Mathematical, physical, and engineering sciences 365 (2007) 539-560. doi:10.1098/rsta.2006.1935

[17] http://www.seika.de/english/index.htm (Accessed 22 August 2012)

[18] W.J.Staszewski, Identification of non-linear systems using multi-scale ridges and skeletons of the wavelet transform. Journal of Sound and Vibration 214 (1998) 639-658.

[19] K.G.Gavin, B.M.Lehane, Base Load-Displacement Response of Piles in Sand. Canadian Geotechnical Journal 44 (2007) 1053-1063.

[20] K.G.Gavin, B.C.O'Kelly, Effect of friction fatigue on pile capacity in dense sand. Journal of Geotechnical and Geoenvironmental Engineering 133 (2007) 63-71.

[21] D.Igoe, K.Gavin, B.O'Kelly, The shaft capacity of pipe piles in sand. Journal of Geotechnical and Geoenvironmental Engineering 137 (2011) 903-912.

[22] K.G.Gavin, A.Tolooiyan, An Investigation of correlation factors linking footing resistance on sand with cone penetration results. Computers and Geotechnics 46 (2012) 84-92.

[23] K.Gavin, A.Adekunte, B.O'Kelly, A field investigation of vertical footing response on sand. Proceedings of the ICE, Geotechnical Engineering 162 (2009) 257-267. 
[24] A.Tolooiyan, K.Gavin, Modelling the Cone Penetration Test in Sand Using Cavity Expansion and Arbitrary Lagrangian Eulerian Finite Element Methods. Computers and Geotechnics 38 (2011) 482-490.

[25] S.Donohue, M.Long, K.Gavin, P.O'Connor, Shear Wave Stiffness of Irish Glacial Till, Proceedings of the International Conference of Site Characterisation I, 2004, pp. 459-466.

[26] P.K.Robertson, Base load-displacement response of piles in sand. Canadian Geotechnical Journal 27 (1997) 151-158.

[27] F.Schnaid, B.M.Lehane, M.Fahey, In situ test characterisation of unusual geomaterials, Proceedings of the International Conference of Site Characterisation I, 2004, pp. 49-73.

[28] S.C.Dutta, R.Roy, A critical review on idealization and modeling for interaction among soilfoundation-structure system. Computers \& Structures 80 (2002) 1579-1594. doi:10.1016/S0045-7949(02)00115-3

[29] Y.W.Kwon, H.Bang, The Finite Element Method using MATLAB, CRC Press, Inc., Boca Raton, FL, 2000, pp. 237-244.

[30] Yang, Vehicle-Bridge Interaction Dynamics, 2004.

[31] G.Gutenbrunner, K.Savov, H.Wenzel, Sensitivity Studies on Damping Estimation, Proceedings of the Second International Conference on Experimental Vibration Analysis for Civil Engineering Structures (EVACES), Porto, Portugal, 2007.

[32] R.V.Dukkipati, Matlab for Mechanical Engineers, New Age Science, 2009.

[33] J.W.Tedesco, W.G.McDougal, C.Allen Ross, Structural Dynamics: Theory and Applications, 1999.

[34] M.Fahey, B.M.Lehane, D.Stewart, Soil Stiffness for shallow foundation design in Perth CBD. Australian Geotechnics Journal 38 (2003) 61-90.

[35] J.Atkinson, Non-linear Soil Stiffness in Routine Design. Géotechnique 50 (2000) 487-508.

[36] S.A.Ashford, T.Juirnarongrit, Evaluation of Pile Diameter Effect on Initial Modulus of Subgrade Reaction. Geotechnical and Geoenvironmental Engineering 129 (2003) 234-242. doi:10.1061/(ASCE)1090-0241(2003)129:3(234)

[37] API, RP2A: Recommended practice for planning, designing and constructing offshore platforms - Working stress design," Washington, DC, 2007.

[38] A.H.Augustesen, K.T.Brødbæk, M.Møller, S.P.H.Sørensen, L.B.Ibsen, T.S.Pedersen, L.Andersen, Numerical Modelling of Large-Diameter Steel Piles at Horns Rev, Proceedings of the Twelfth International Conference on Civil, Structural and Environmental Engineering Computing, 2009, pp. 1-14.

[39] L.C.Reese, H.Matlock, Non-dimensional Solutions for Laterally Loaded Piles with Soil Modulus Assumed Proportional to Depth, Proceedings of the 8th International Conference on Soil Mechanics and Foundation Engineering, 1956, pp. 1-41.

[40] J. M. Murchison, M.W. O’Neill, Evaluation of p-y relationships in cohesionless soils, Analysis and Design of Pile Foundations. Proceedings of a Symposium in conjunction with the ASCE National Convention, 1984, pp. 174-191.

[41] D.Kallehave, C.L.Thilsted, M.A.Liingaard, Modification of the API P-Y Formulation of Initial Stiffness of Sand, Proceedings of the 7th International Conference on Offshore Site Investigations and Geotechnics, London, 2012, pp. 465-472.

[42] A.H.Augustesen, M.Moller, K.T.Brodbaek, and S.P.H.Sorensen, Review of laterally loaded mono-piles employed as the foundation for offshore wind turbines, 2012.

[43] B.W.Byrne, C.Leblanc, G.T.Houlsby, Response of stiff piles in sand to long-term cyclic lateral loading. Géotechnique 60 (2010) 79-90. doi:10.1680/geot.7.00196

[44] K.Gavin, P.Doherty, Laterally loaded monopile design for offshore wind farms. Proceedings of the ICE - Energy 165 (2012) 7-17. doi:10.1680/ener.11.00003

[45] M.Fahey, Shear modulus of cohesionless soil: variation with stress and strain level. Canadian Geotechnical Journal (1992).

[46] P.K.Roy, N.Ganesan, Transient response of a cantilever beam subjected to an Impulse Load. Journal of Sound and Vibration 183 (1995) 873-880. 